\title{
Rome Foundation Working Team Report on Post-Infection Irritable Bowel Syndrome
}

\author{
Giovanni Barbara, ${ }^{1}$ Madhusudan Grover, ${ }^{2}$ Premysl Bercik, ${ }^{3}$ Maura Corsetti, ${ }^{4}$ \\ Uday C. Ghoshal, ${ }^{5}$ Lena Ohman, ${ }^{6}$ and Mirjana Rajilić-Stojanović ${ }^{7}$
}

${ }^{1}$ Department of Medical and Surgical Sciences, University of Bologna, Bologna, Italy; ${ }^{2}$ Enteric NeuroScience Program, Division of Gastroenterology and Hepatology, Mayo Clinic, Rochester, Minnesota; ${ }^{3}$ Department of Medicine, Farncombe Family Digestive Health Research Institute, McMaster University, Hamilton, Ontario, Canada; ${ }^{4}$ Nottingham Digestive Diseases Biomedical Research Centre, National Institute for Health Research, Nottingham University Hospitals NHS Trust, University of Nottingham, UK; ${ }^{5}$ Department of Gastroenterology, Sanjay Gandhi Post Graduate Institute of Medical Sciences, Lucknow, India; ${ }^{6}$ Department of Microbiology and Immunology, Sahlgrenska Academy, University of Gothenburg, Gothenburg, Sweden; and ${ }^{7}$ Department of Biochemical Engineering and Biotechnology, Faculty of Technology and Metallurgy, University of Belgrade, Belgrade, Serbia

\section{See editorial on page 14.}

BACKGROUND \& AIMS: The existence of postinfection irritable bowel syndrome (PI-IBS) has been substantiated by epidemiology studies conducted in diverse geographic and clinical settings. However, the available evidence has not been well summarized, and there is little guidance for diagnosis and treatment of PI-IBS. The ROME Foundation has produced a working team report to summarize the available evidence on the pathophysiology of PI-IBS and provide guidance for diagnosis and treatment, based on findings reported in the literature and clinical experience. METHODS: The working team conducted an evidence-based review of publication databases for articles describing the clinical features (diagnosis), pathophysiology (intestinal sensorimotor function, microbiota, immune dysregulation, barrier dysfunction, enteroendocrine pathways, and genetics), and animal models of PI-IBS. We used a Delphi-based consensus system to create guidelines for management of PI-IBS and a developed treatment algorithm based on published findings and experiences of team members. RESULTS: PI-IBS develops in about $10 \%$ of patients with infectious enteritis. Risk factors include female sex, younger age, psychological distress during or before acute gastroenteritis, and severity of the acute episode. The pathogenesis of PI-PBS appears to involve changes in the intestinal microbiome as well as epithelial, serotonergic, and immune system factors. However, these mechanisms are incompletely understood. There are no evidence-based, effective pharmacologic strategies for treatment of PI-IBS. We provide a consensus-based treatment algorithm, based on clinical presentation and potential disease mechanisms. CONCLUSIONS: Based on a systematic review of the literature and team experience, we summarize the clinical features, pathophysiology (from animal models and human studies), and progression of PI-IBS. Based on these findings, we present an algorithm for diagnosis and treatment of PI-IBS based on team consensus. We also propose areas for future investigation.

Keywords: Gastrointestinal Infection; Microbiome; Campylobacter; Serotonin; Barrier Function.
Tritable bowel syndrome (IBS) is one of the most common conditions diagnosed in gastroenterology practice. The prevalence of IBS ranges between $7 \%$ and $16 \%$ in Western countries and is more common in females and younger individuals. Although the etiology of IBS is still obscure, its pathophysiology is dominated by a combination of both psychological factors and gastrointestinal dysfunction. Recent efforts have allowed identification of several peripheral microorganic abnormalities. These include changes in gut microbiota, low-grade mucosal inflammation, and epithelial dysfunction. Additionally, genetic polymorphisms and environmental factors, including dietary factors and enteric infections, have been shown to play a role. The identification of these factors and their interaction with the brain has opened an entirely new era in the understanding, recognition, and legitimization of IBS and functional gastrointestinal disorders (FGIDs) at large. As a consequence, there has been agreement among experts to eliminate the term functional from the recently released Rome IV criteria and redefine these conditions as disorders of gut-brain interactions.

Acute infectious gastroenteritis represents the strongest known risk factor for IBS development, a condition known as postinfection IBS (PI-IBS). Although publications from the past often alluded to the possibility that irritability of the gut could develop in the aftermath of a bacillary diarrheal episode, ${ }^{2,3}$ the first formal description of PI-IBS was published in 1962 by Chaudhary and Truelove. ${ }^{4}$ There was a relative quiescence in this research area until the late 1990s,

Abbreviations used in this paper: 5-HT, 5-hydroxytryptamine (serotonin); CCK, cholecystokinin; CdtB, cytolethal distending toxin B; CI, confidence interval; EC, enterochromaffin; FD, functional dyspepsia; FGID, functional gastrointestinal disorder; IBS, irritable bowel syndrome; IBS-C, irritable bowel syndrome with constipation; IBS-D, irritable bowel syndrome with diarrhea; IBS-M, irritable bowel syndrome mixed; ICC, interstitial cells of Cajal; IL, interleukin; PI-FD, postinfection functional dyspepsia; PI-IBS, postinfection irritable bowel syndrome; RFWT, Rome Foundation Working Team; SNP, single-nucleotide polymorphism; Th, T helper.

Most current article

\section{(C) 2019 by the AGA Institute} 0016-5085/\$36.00

https://doi.org/10.1053/j.gastro.2018.07.011 


\section{WHAT YOU NEED TO KNOW \\ BACKGROUND AND CONTEXT}

Infectious gastroenteritis may lead to post-infection functional gastrointestinal disorders (PI-FGID), such as irritable bowel syndrome and/or functional dyspepsia, in about 1 in 10 people infected. The pathophysiology, diagnosis and management of these clinical entities is poorly defined.

\section{NEW FINDINGS}

Post-infection IBS was defined with Rome IV criteria. An evidence-based review of publications and a Delphi consensus process was created to summarize pathophysiology, guide diagnosis and provide a treatment algorithm.

\section{LIMITATIONS}

The mechanisms, risk factors and potential genetic predisposition for PI-FGID remain only partly elucidated. There are no available biomarkers and no specific treatments for PI-FGID.

\section{IMPACT}

These findings will inform further research into mechanistic and diagnostic aspects of PI-FGID and provide a framework for its clinical management.

when elegant observations were made to explain the role of peripheral and central factors in the development of IBS after intestinal infections. ${ }^{5-7}$ Several subsequent studies have described PI-IBS in a wide variety of settings summarized in a recently published meta-analysis. ${ }^{8}$ Approximately $10 \%$ of those with intestinal infection who respond to survey questionnaires endorse symptoms consistent with PI-IBS. ${ }^{8}$ These estimates have varied with the type of pathogen involved, and some studies have shown estimates as high as 35\%-45\% for PI-IBS development. ${ }^{9,10}$ The exact burden of PI-IBS is hard to assess: there is poor recall of intestinal infections, and no biomarkers have been identified. Conservative estimates suggest that PI-IBS contributes to as much as $9 \%$ of the overall number of IBS cases in the community. ${ }^{11}$

Compared with the epidemiologic literature, pathophysiological mechanisms of PI-IBS have been relatively understudied. Larger outbreaks have provided numbers needed to investigate genetic associations that identified single nucleotide polymorphisms (SNPs) associated with PI-IBS, although significance levels did not withstand multiple-testing correction. ${ }^{12}$ PI-IBS mechanistic studies in humans have provided evidence in support of increased intestinal permeability, ${ }^{13-15}$ altered serotonin (5-HT) metabolism, ${ }^{16-18}$ and increased density of lamina propria enterochromaffin (EC) cells $^{19,20}$ and T lymphocytes. ${ }^{15}$ Animal studies have postulated on the role of Campylobacter toxin ${ }^{21}$ and putative mechanisms including small intestinal bacterial overgrowth ${ }^{22}$ and loss of interstitial cells of Cajal (ICCs). ${ }^{23}$ ICCs are the key regulators of gastrointestinal motility through generation and propagation of electrical slow waves, and they mediate communication between the autonomic nervous system and smooth muscle cells. ${ }^{24}$ Animal models have used Citrobacter rodentium, Trichinella spiralis, and Campylobacter species as prototypical organisms to investigate host interactions at the peripheral and spinal levels. ${ }^{25}$

Psychological factors like anxiety, depression, somatization, and neuroticism during or in the preceding months before infection have been associated with PI-IBS development, as noted in a recent meta-analysis. ${ }^{8}$ Concomitant stress has also been associated with altered neuronal plasticity at the spinal level in animal models of PI-IBS. ${ }^{26} \mathrm{~A}$ recent study showed that psychological stress may be a risk factor for enteritis itself, and a unique cytokine milieu favoring T-helper (Th) type 2 immune response may exist during psychological stress. ${ }^{27}$ Except for corticosteroids ${ }^{28}$ and mesalamine, ${ }^{29}$ randomized controlled trials with PI-IBS patients have not been conducted.

The Rome Foundation commissioned a working team to help advance understanding of PI-IBS. This review is a summary of existing knowledge with an emphasis on the clinical features, diagnosis, animal studies, host-response mechanisms (including microbiota, immune regulation, and genetic factors), and treatment of PI-IBS. The epidemiology, risk factors, and natural history were extensively reviewed in the recent meta-analysis and are only briefly summarized here. ${ }^{8}$

\section{Clinical Features}

\section{Diagnosis}

Although there is no validated definition of PI-IBS, this condition is characterized by new-onset, Rome criteriapositive IBS after an episode of acute gastroenteritis in individuals who did not have IBS before the infection. The diagnostic criteria for PI-IBS proposed by the Rome Foundation Working Team (RFWT) are based on the Rome IV criteria. These criteria were not part of the original Rome IV document, because they were prepared after the release of the Rome IV publications (Table 1). These criteria need to be fulfilled for the last 3 months with symptom onset at least 6 months before diagnosis. ${ }^{30}$ Acute infectious gastroenteritis is ideally diagnosed by stool culture (although only occasionally obtained in community subjects), validated molecular biology analyses (e.g., polymerase chain reaction), or by the presence of $\geq 2$ of the following: fever, vomiting, or diarrhea. $^{31}$

Subtyping IBS according to bowel habit has important implications to guide management. Generally, IBS is subtyped according to bowel habit based on the Bristol Stool Form Scale, in 3 categories: IBS with constipation (IBS-C), with diarrhea (IBS-D), and with mixed bowel habit (IBS-M) ${ }^{30}$ Most studies report IBS-M as the most predominant pattern associated with PI-IBS. ${ }^{8}$ The next most common is the IBS-D category, and the reminder of the studies $(<10 \%)$ reported IBS-C. ${ }^{20}$ The IBS-D subtype has been found to remain stable over time. ${ }^{32}$ Although a phenotypic switch over time may frequently occur among the different bowel habit subtypes in IBS, whether the same applies to PI-IBS remains to be investigated. According to the Rome Foundation Multi-Dimensional Clinical Profile, ${ }^{33}$ PI-IBS constitutes part of the category of clinical modifiers. 
Table 1.Diagnostic Criteria for Postinfection Irritable Bowel Syndrome (Based on Rome IV)

1. Recurrent abdominal pain, on average, at least 1 day per week in the last 3 months, with symptom onset at least 6 months before diagnosis, associated with $\geq 2$ of the following:

a) defecation

b) a change in frequency of stool

c) a change in form (appearance) of stool

2. Symptom development immediately after resolution of acute infectious gastroenteritis

3. Infectious gastroenteritis defined by positive stool culture in a symptomatic individual or presence of $\geq 2$ of the following acute symptoms (when stool culture not available) ${ }^{a}$ :

a) fever

b) vomiting

c) diarrhea

4. Should not meet criteria for IBS before onset of acute illness ${ }^{b}$

${ }^{a} \mathrm{~A}$ recollection of the precise date of onset of IBS symptoms can also be suggestive of PI-IBS

${ }^{b}$ Some patients may experience irregular bowel movements before onset of acute illness (but not associated with the frequent pain characteristic of IBS) that can still be defined as developing PI-IBS.

\section{Differential Diagnosis}

In typical cases of PI-IBS without alarm features, physicians are encouraged to make a diagnosis without significant additional diagnostic assessment. A few patients may undergo fecal tests to exclude a chronic parasitic or protozoal infection, especially chronic giardiasis. However, stool cultures are unlikely yield positive results, because long-lasting infections with Campylobacter, Shigella, Salmonella, or Yersinia species are uncommon. Limited testing may include a complete blood count and C-reactive protein and fecal calprotectin levels. However, in cases with severe or alarm symptoms like significant $(>10 \%)$ weight loss, gastrointestinal bleeding, or failure to respond to drugs commonly used in IBS, further investigations may be required.

Details on differential diagnosis are provided in the supplementary material. Figure 1 provides a diagnostic algorithm for evaluation of PI-IBS.

\section{Prevalence}

The prevalence of PI-IBS among those suffering from infectious enteritis has been estimated between $4 \%$ and $36 \%{ }^{31}$ However, because episodes of infectious gastroenteritis occur quite frequently during lifetime (e.g., 1.4 episode/year/subject) and because IBS patients may be unable to recall milder and remote episodes of gastroenteritis, we hypothesize that the true pathogenetic role of gastrointestinal infections in IBS is higher than currently estimated.

A recent systematic review of 45 studies, comprising approximately 21,000 individuals with enteritis who were followed up for 3 months to 10 years, found a pooled prevalence of IBS at 12 months after infectious enteritis of $10.1 \%$ (95\% confidence interval [CI], 7.2-14.1). ${ }^{8}$ Figure 2 illustrates geographic variations in PI-IBS prevalence by pathogen type. Studies examining a follow up $>12$ months after infectious enteritis found a pooled prevalence of PI-IBS of $14.5 \%$ ( $95 \%$ CI, 7.7-25.5). Thirty out of the 45 studies that examined the relative risk of developing IBS compared with a cohort of uninfected patients showed a 4.2-fold risk for developing IBS over 12 months of follow-up, which decreased to 2.3 -fold in studies that extended beyond 12 months (Supplementary Figure 1). PI-IBS has more frequently been described as a consequence of bacterial than viral infection, ${ }^{34}$ which is in contrast to the higher prevalence of viral compared with bacterial etiology of infectious diarrhea. This could be explained by the fact that mucosal damage and inflammation caused by bacterial gastroenteritis is often greater than that caused by viral agents. $^{31}$ Recently, PI-IBS has also been described after Clostridium difficile infection in up to $25 \%$ of cases. ${ }^{35,36}$ Additionally, Vibrio cholerae has recently been associated with PI-IBS development in $16.5 \%$ of cases as well. ${ }^{37}$ Although most studies describing PI-IBS have been conducted in adult subjects, PI-IBS has also been described in the pediatric population, with younger age representing a risk for persistence of IBS symptoms in the long term (16 years) compared with adults. ${ }^{38,39}$

Functional dyspepsia (FD), another common FGID, is characterized by postprandial fullness, early satiation, epigastric pain, and epigastric burning. ${ }^{40}$ IBS has been found to overlap with FD in up to $50 \%$ of patients, ${ }^{41}$ and the occurrence of PI-FD has also been described. ${ }^{42} \mathrm{~A}$ recent systematic review reported that the prevalence of PI-FD was similar to that of PI-IBS (9\%); however, the risk of developing PI-FD was lower than that of developing PI-IBS $(2.5$; 95\% CI, $1.8-3.6$ vs 3.5 ; 95\% CI, 2.0-6.0). ${ }^{43}$ Moreover, the risk of overlapping PI-FD and PI-IBS was higher in children than in adults $(39 \%$; $95 \% \mathrm{CI}, 35-90$ vs 13 ; range, $8 \%-$ $42 \%)^{43}$ In a more recent article, the prevalence of PI-FD was $26 \%$ in the exposed individuals vs $7 \%$ in unexposed individuals, with a relative risk of 3.9 (95\% CI, 3.1-4.8) after Giardia species infection. ${ }^{44}$ Among individuals fulfilling criteria for PI-IBS, $44 \%$ in the exposed group and $29 \%$ in the control group also fulfilled criteria for PI-FD. ${ }^{44}$

\section{Risk Factors}

Specific demographic, psychological, and clinical factors related to the enteritis episode have been found to be associated with the risk of PI-IBS. A recent meta-analysis provided pooled summary estimates for these associated factors, ${ }^{8}$ and a summary of these and the natural history of 


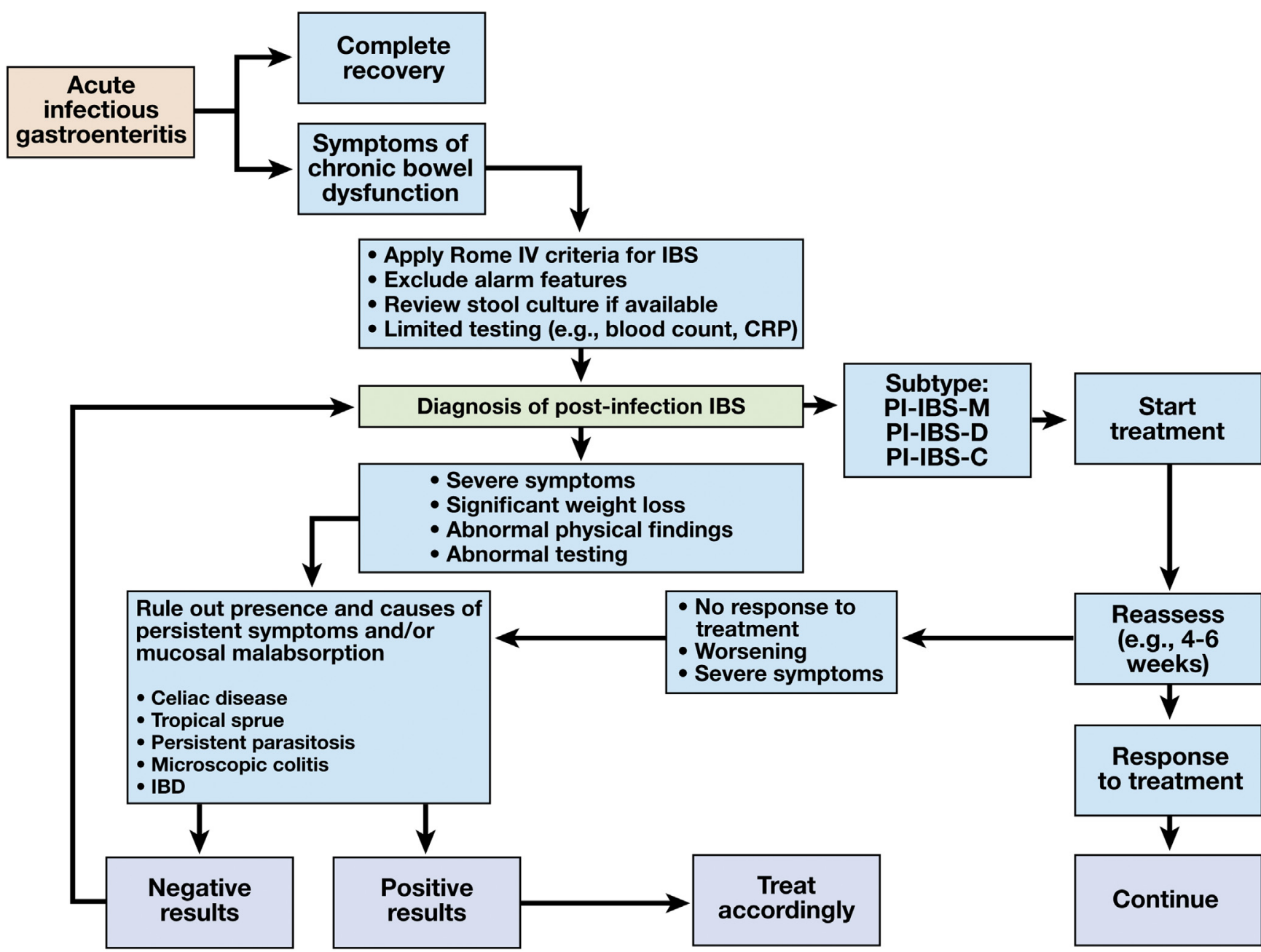

Figure 1. Rome IV diagnostic algorithm for postinfection irritable bowel syndrome.

PI-IBS is provided in the supplementary material and Supplementary Figure 1.

\section{Pathophysiology}

PI-IBS is a complex and likely multifactorial disorder. Studies on the pathophysiology have been performed in small groups of patients and at different time points postinfection, which may contribute to incomplete information. The pathophysiology of PI-IBS is dominated by the interaction between the central and peripheral factors, the latter including the microbiota, epithelial, enteroendocrine, immunologic, and neuromotor mechanisms. It is currently unknown if there are unique pathophysiological mechanisms for PI-IBS. Animal models have been instrumental for understanding the mechanisms underlying gut and behavioral dysfunction after acute infection. Figure 3 provides a conceptual framework for neuroimmune interactions in PI-IBS.

\section{Gut Dysmotility and Visceral Hypersensitivity}

Although gut dysmotility and visceral hypersensitivity are considered to be important in the pathophysiology of IBS, ${ }^{30}$ only a few studies have assessed bowel physiology in PI-IBS. ${ }^{45}$ Gwee et $\mathrm{al}^{6}$ described the presence of persistent rectal hyperreactivity and hypersensitivity 3 months after an infection and associated it with PI-IBS development. Further studies need to evaluate whether the described motor or sensory dysfunctions are indeed characteristics of PI-IBS.

\section{Microbiota}

The gut microbiota has a remarkable ability to resist to environmental perturbation and to preserve its structure and function. ${ }^{46}$ This is best illustrated through the preserved individual specific microbiota signature over a decade $^{47,48}$ and after broad-spectrum antibiotics. ${ }^{49}$ Ecosystem resilience also occurs after recovery from an intestinal infection. However, those developing PI-IBS may have a primary inability to restore the microbial ecosystem or a secondary inability to restore gut microbiota because of host factors. Figure 4 illustrates this conceptual framework.

A recent study showed that PI-IBS patients have dysbiosis. However, these microbial signatures are different from those described in IBS patients in general. ${ }^{50}$ In addition, the susceptibility to infection has been linked to microbiota composition. In poultry abattoir workers who are susceptible to infection, there were increased levels of bacteria belonging to the Bacteroidetes phylum. ${ }^{51}$ This 


\section{Worldwide prevalence of PI-IBS}

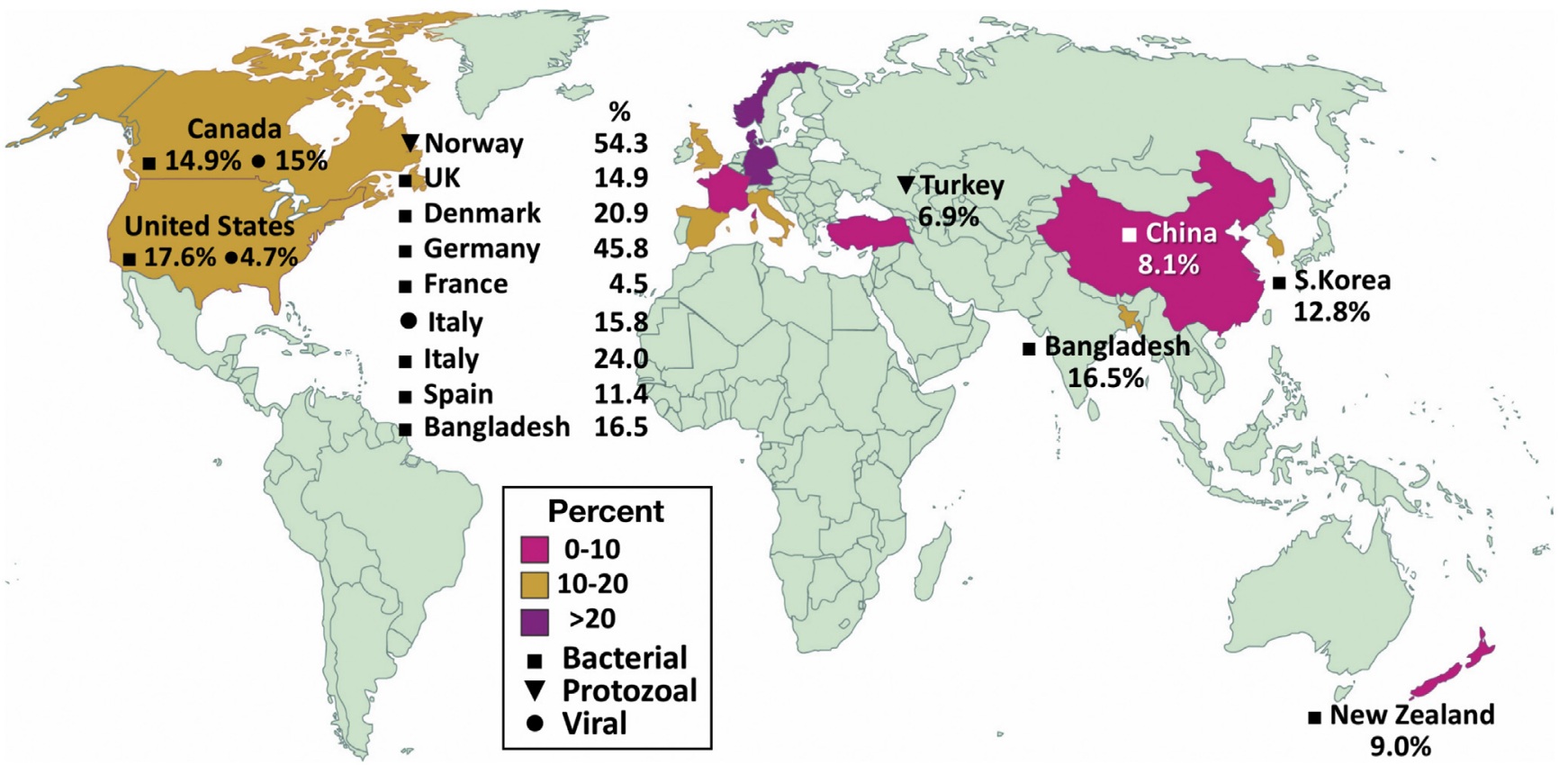

Figure 2. Geographic distribution of postinfection irritable bowel syndrome prevalence by pathogen type.

phylum is also abundant in PI-IBS patients but not in IBS patients who have an increased Firmicutes to Bacteroidetes ratio. $^{52-54}$ Conversely, travelers who develop infectious diarrhea have low levels of Bacteroidetes, suggesting possible protective effect of Bacteroidetes. ${ }^{55}$ The incidence of PI-IBS after traveler's diarrhea is 2-fold lower than after other cases of gastroenteritis. ${ }^{56}$
Among the butyrate-producing bacteria, Subdoligranulum variable was found to be depleted in PI-IBS patients. $^{54}$ This bacterium was found to stimulate interleukin (IL)-1 $\beta$ (proinflammatory cytokine) production in biopsy samples obtained from PI-IBS patients but not in those obtained from healthy individuals. ${ }^{57}$ This indicates a specific activity of the hosts' immune system against a
A

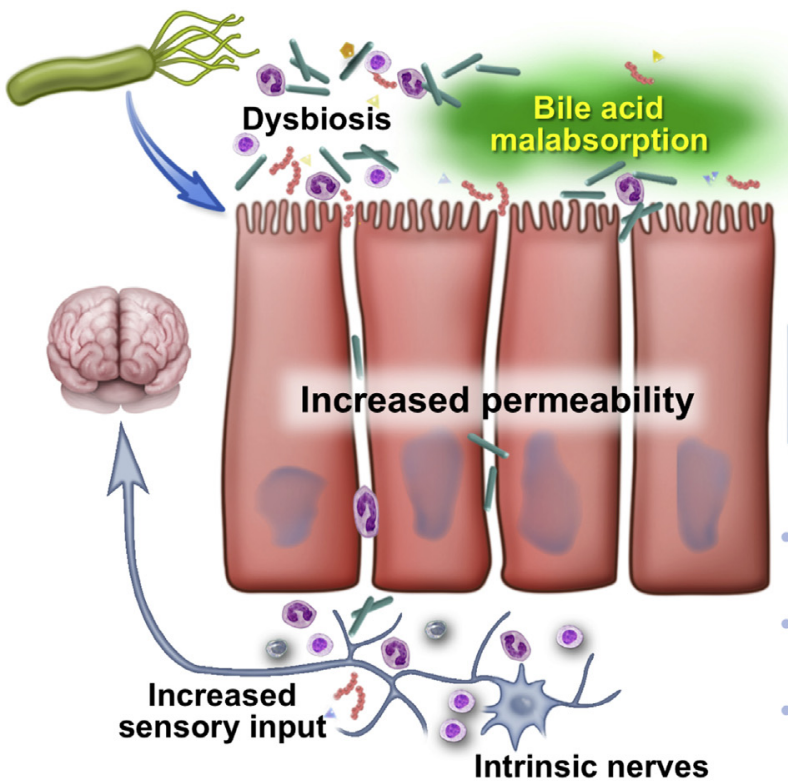

Acute inflammation

\section{B Acute infection IBS}

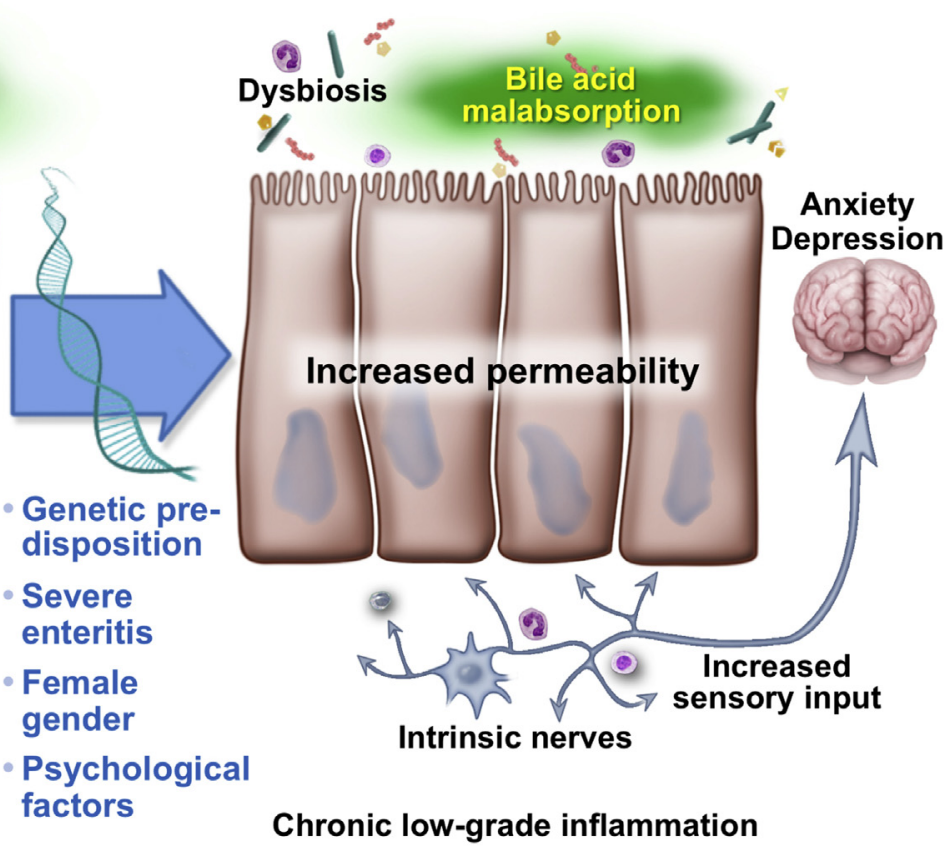

Figure 3. Schematic representation of putative pathophysiology underlying postinfection irritable bowel syndrome. 


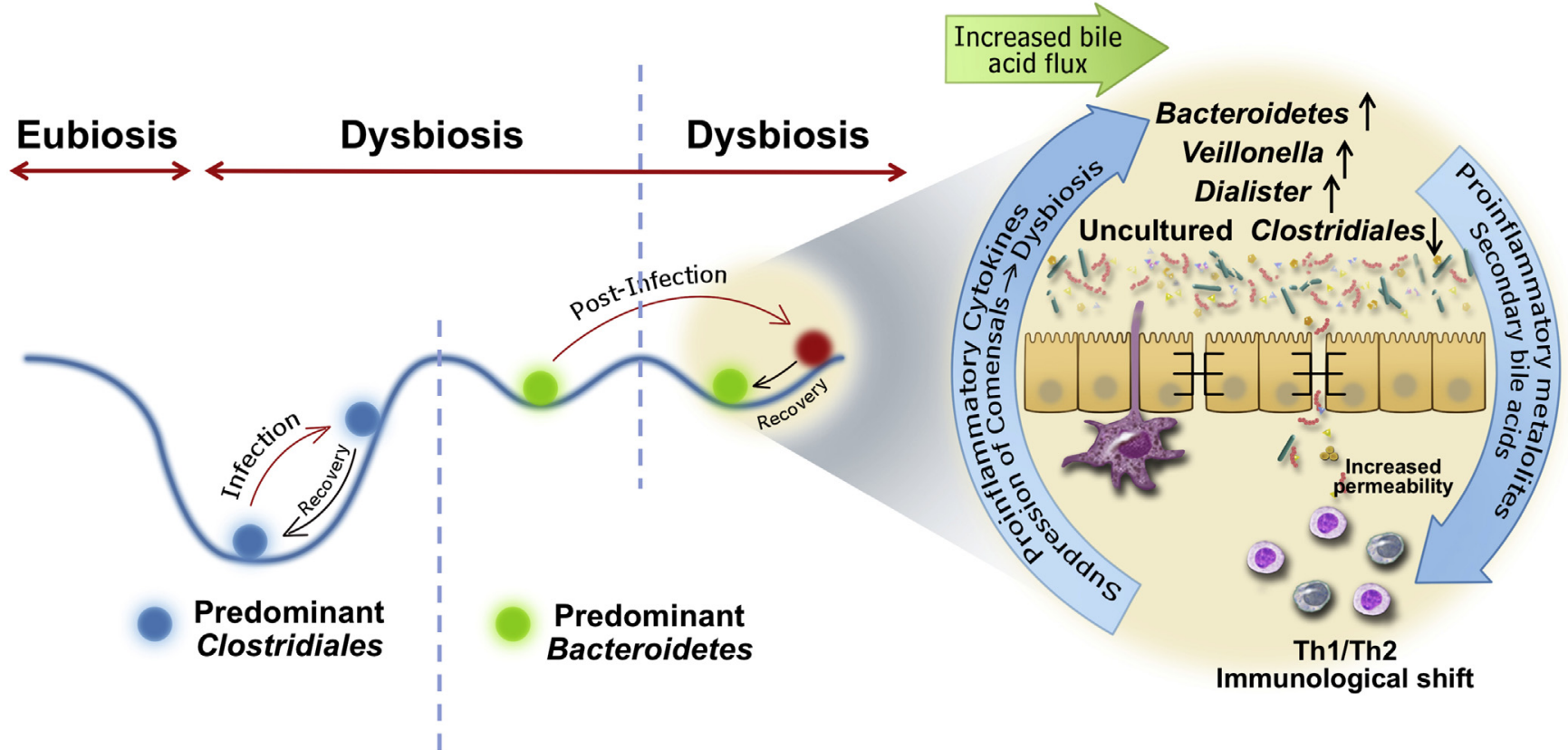

Figure 4. Putative role of infection-associated shifts in microbial community in postinfection IBS. A host with a Clostridialespredominant microbiota type is likely to remain in the eubiosis state after infection, whereas, presence of a Bacteroidetespredominant community may predispose to development of long-term dysbiosis upon infection. Dysbiosis can then result in shifts in bile acid composition and the cytokine and immune milieu, which can affect epithelial and neuromuscular function and further perpetuate dysbiosis.

symbiotic microbe during pathologic conditions and suggests a complex and bipolar interaction between microbiota and immune responses in PI-IBS.

\section{Intestinal Permeability and Immune Dysregulation}

A subset of PI-IBS patients has markedly increased in vivo permeability, as assessed by the lactulose-mannitol excretion ratio. ${ }^{13-15}$ Longitudinal follow-up studies after bacterial enteritis showed that increased intestinal permeability subsides over time except in those who develop PIIBS. ${ }^{15}$ Increased intestinal permeability is considered an early event associated with low-grade immune activation. Although a state of physiologic inflammation is considered normal, several studies in patients with IBS and PI-IBS have shown the presence of low-grade intestinal immune activation.

The innate immune system, including mast cells and macrophages, has been reported to be altered in the intestinal mucosa of PI-IBS patients. For example, PI-IBS patients have been reported to have reduced numbers of resident $\mathrm{CD}^{15}{ }^{15}$ and calprotectin-positive macrophages compared with healthy individuals. ${ }^{58}$ Additionally, the number of mast cells surrounded by nerve fibers in the terminal ileum mucosa has been shown to be increased in PI-IBS patients compared with healthy individuals. ${ }^{59}$ Studies have also suggested that the close interaction between nerves and mast cells correlate with abdominal bloating and pain. ${ }^{60,61}$

Other investigations have focused on the involvement of adaptive immunity in PI-IBS. Numbers of lamina propria T lymphocytes has been shown to be higher in patients with PI-IBS compared with healthy volunteers. ${ }^{19}$ Furthermore,
T-lymphocyte counts in both lamina propria and epithelium have been reported to be increased relative to healthy individuals. ${ }^{15,58}$ Moreover, PI-IBS patients showed significantly increased frequency of activated/memory CD $45^{+} \mathrm{T}$ cells and decreased frequency of B cells in colonic lamina propria. ${ }^{62}$ It has also been reported that the frequencies of lymphocytes in the epithelial lining and lamina propria are negatively correlated with mucosal microbial diversity, suggesting an interaction between the microbiota and immune activation in PI-IBS. ${ }^{63}$ Cytolethal distending toxin B (CdtB) is produced by bacteria that cause acute gastroenteritis. Host antibodies to CdtB cross-react with vinculin. In a recent study, plasma levels of anti-CdtB and anti-vinculin antibodies were found to be significantly higher in patients with IBS-D than in those with inflammatory bowel disease, those with celiac disease, and healthy control individuals, suggesting that these antibodies could be used as relevant biomarkers in distinguishing IBS-D from other pathologic conditions in the workup of chronic diarrhea. ${ }^{64}$ Another study showed a higher prevalence of antibodies to the flagellin antigen (types A4-Fla2 and Fla-X) in IBS patients, especially those with a history of preceding gastroenteritis episode vs those without. ${ }^{65}$ However, validation of these antibodies or another biomarker has not been performed specifically in PI-IBS.

An altered cytokine expression in serum or intestinal mucosa may be seen as a result of altered activation of the immune response. Mucosal IL-1 $\beta$ mRNA expression has been reported to be higher in PI-IBS patients than in healthy individuals. ${ }^{59}$ Furthermore, an increased mucosal level of interferon gamma and a decreased level of IL-10 were reported in PI-IBS patients, suggesting involvement of the Th1 
cells and Th2 cells, respectively. ${ }^{66}$ Furthermore, the release of IL-13 (Th2 cell-mediated cytokine) from mucosal biopsy samples was lower in PI-IBS patients than in healthy individuals. After stimulation with the bacteria $S$ variabile or Eubacterium limosum, biopsy samples from PI-IBS patients resulted in higher IL-1 $\beta$ and lower IL-10 release than biopsy samples from healthy individuals. This implies a possible role of altered immune response against commensal gut microbes in the pathophysiology of PI-IBS. ${ }^{57}$

\section{Enteroendocrine Pathways}

EC cells are key regulators of many gut functions, particularly motility and sensory perception, with 5-HT (5hydroxytryptamine or serotonin) being a key signaling molecule. Recent data suggest that in addition to host production of 5-HT, gut commensals, including the sporeforming Clostridiales order within the Firmicutes phylum may regulate 5 -HT synthesis. ${ }^{67}$ Changes in 5 -HT metabolism have been detected in patients with PI-IBS. Colonic EC cell counts were higher in patients with Campylobacter-associated PI-IBS than in healthy individuals, and EC cell counts were also positively correlated with CD3 T-cell counts. ${ }^{15,20}$ In Shigella-associated PI-IBS, 5-HT-containing EC cells and peptide YY-containing EC cells, were increased compared with healthy individuals. ${ }^{58}$ However, the role of gut hormones in PI-IBS remains controversial, because another study showed that patients with Giardia-associated PI-IBS have lower numbers of duodenal EC cells but increased numbers of cholecystokinin (CCK)-positive cells. ${ }^{16}$ Further study is needed to determine whether different pathogen types or different sites within the intestinal tract after infection with the same pathogen elicit variable responses to an injury.

\section{Genetics}

The Walkerton outbreak cohort examined functional gene variants in 79 genes and their associations with the PIIBS phenotype. Four variants, 2 in toll-like receptor 9 (pattern recognition receptor) and one each in IL-6 (preinflammatory cytokine) and CDH1 (tight junction protein), were associated with PI-IBS independently of clinical risk factors. However, these genes were not found to be significantly associated with PI-IBS after correction for the total number of SNPs. ${ }^{12}$ Another study reported association between tumor necrosis factor- $\alpha$ SNP and Campylobacter jejuni PI-IBS, but these results need to be confirmed in larger studies. ${ }^{68}$

\section{Animal Models}

Several mouse models of PI-IBS using parasitic and bacterial infections mimic certain aspects of the gut dysfunction and low-grade immune activation observed in patients. None of these models entirely recapitulates the full spectrum of IBS symptoms, and each of them provides certain advantages over the others. Figure 5 summarizes animal models for PI-IBS.

\section{T spiralis Model}

$T$ spiralis is a nematode parasite that transiently infects the gastrointestinal tract of rats and mice and induces chronic inflammation and gut dysfunction that is maintained after the parasite expulsion. ${ }^{69}$ The effects on the host are genetically influenced, because some mouse strains, such as outbred NIH Swiss mice, display more pronounced changes in gut function than other strains. ${ }^{70} T$ spiralis induces longterm neuromuscular dysfunction, characterized by muscle hypercontractility and altered release of acetylcholine that persist for up to 42 days infection. ${ }^{71,72}$ These functional changes are immune mediated and depend, among others, on $\mathrm{T}$ lymphocytes and macrophage colony stimulating factor-derived macrophages. ${ }^{73-76}$ Although several Th2 cytokines play an important role during the acute phase of the infection, it is the transforming growth factor- $1 \beta$-mediated up-regulation of cyclooxygenase 2 within the muscularis propria that maintains the persistent neuromuscular dysfunction. $^{74,77} \mathrm{~T}$ spiralis infection affects the ICC network, leading to disorganized motor patters and ectopic pacemakers with occurrence of retrograde peristalsis. ${ }^{69,78,79}$ Visceral hyperalgesia also develops as a consequence of $T$ spiralis infection, and it can be maintained for up to 72 days, together with gut dysmotility by administration of crude $T$ spiralis antigen. ${ }^{69}$ Apart from changes within the cholinergic nerves, $T$ spiralis alters functions of the sensory nerves and serotonergic system, with increased 5-HT content and release, altered expression of 5-HT(3) receptors, ${ }^{17}$ reduced serotonin reuptake transporter expression, ${ }^{18}$ and overall changes in synaptic plasticity. ${ }^{80}$ The changes in the enteric nervous system have been linked to long-lasting changes in epithelial transport, with altered secretion responses to stimulation using electrical field and secretagogues. ${ }^{81}$

Although the $T$ spiralis model recapitulates most of the pathophysiological aspects seen in PI-IBS patients, its disadvantage is the fact that $T$ spiralis larvae penetrate the intestine and enter the systemic circulation and the brain. Thus, at least part of the immune responses and the accompanying gut dysfunction seen in this model could originate from systemic immune responses.

\section{Nippostrogylus brasiliensis Model}

$N$ brasiliensis is another nematode parasite that infects rodents and induces several aspects of gut dysfunction in both rats and mice. At 30 days after infection, $N$ brasiliensis induced changes in small intestinal migrating myoelectrical complexes that were associated with jejunal mastocytosis and enteric nerve remodeling, ${ }^{82}$ as well as altered responses to cholecystokinin stimulation. ${ }^{83} \mathrm{~N}$ brasiliensis also induced changes in visceral sensitivity, including alterations in neurokinin receptors and mast cells, ${ }^{84,85}$ but these changes did not persist at 90 days after infection. $N$ brasiliensis infection induced long-term changes in the tetrodotoxinresistant sodium channel in the dorsal root ganglia neurons, ${ }^{86}$ as well as altered chemosensitivity and afferent vagal signaling. ${ }^{87}$ Although this model clearly shows changes in visceral sensitivity, the effects are relatively short lasting and mainly affect the small bowel. 
Figure 5. Summary of animal models for postinfection irritable bowel syndrome. Various pathogen types have unique or overlapping mechanisms associated with irritable bowel syndrome. The proximity to the center reflects the strength of association.

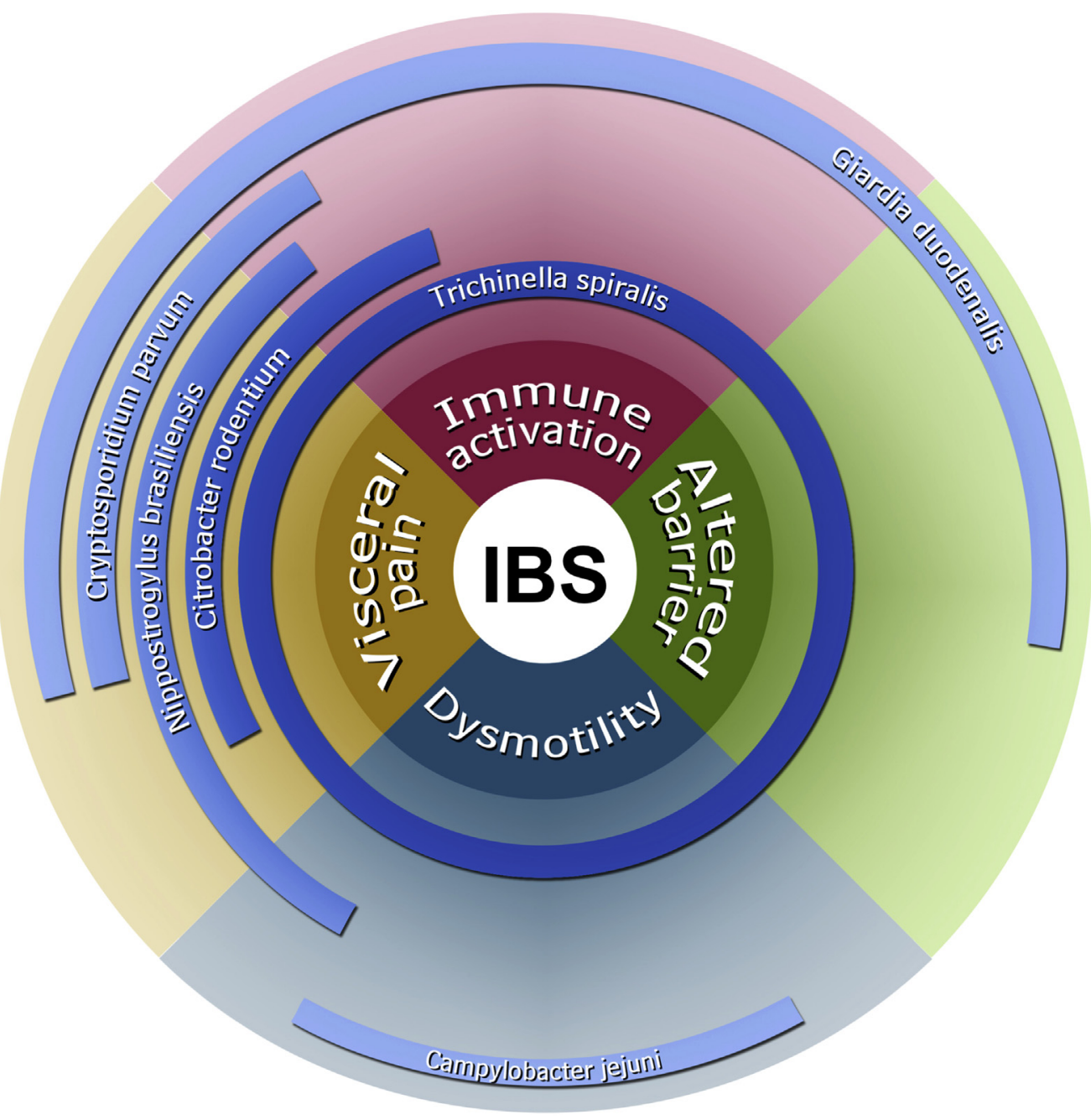

\section{Cryptosporidium parvum Model}

$C$ parvum is an intracellular protozoan parasite affecting mainly the distal small intestine. Newborn rats infected by $C$ parvum displayed jejunal hypersensitivity to jejunal distension 120 days after infection, which was associated with an increase in activated mast cells. ${ }^{88,89}$ Treatment with octreotide at 10 days after infection normalized visceral hypersensitivity, immune cell numbers, and changes in the structure of the enteric nervous system. ${ }^{89}$ No changes in intestinal motility or permeability in the postinfection stage were reported in this model.

\section{Giardia duodenalis Model}

$G$ duodenalis is a flagellated parasite that infects the small intestine of both humans and rodents. Neonatal rats infected with $G$ duodenalis developed visceral hypersensitivity in both jejunum and rectum at day 50 after infection. This was associated with changes in intestinal barrier function and increased intraepithelial lymphocytes and mast cells in the jejunum. ${ }^{90} G$ duodenalis infection also induced short-term alterations of gut microbiota composition and long-term changes in mucosal adherence and endocytosis of bacteria, which was accompanied by up-regulation of mucosal proinflammatory cytokines. ${ }^{91}$ This model shows widespread changes in visceral sensitivity and microbiotahost interaction, but no effect of $G$ duodenalis on motility was shown.

\section{C jejuni Model}

In a rat model, $C$ jejuni infection induced long-lasting changes in gut microbiota reminiscent of small-intestinal bacterial overgrowth, alterations in ICC counts, and changes in stool consistency, ${ }^{21,23,92}$ which were suggestive of intestinal dysmotility. Prophylactic treatment with rifaximin then ameliorated changes in stool consistency. ${ }^{93}$ However, this model so far has not shown any direct changes in motility, permeability, or visceral sensitivity.

\section{C rodentium Model}

$C$ rodentium is a mouse equivalent of human enteropathogenic Escherichia coli. Mice infected with $C$ rodentium and then submitted to chronic water avoidance test developed visceral hypersensitivity, as assessed by measuring colonic dorsal root ganglia neuronal excitability and changes 
in multiunit afferent recordings. ${ }^{26}$ This was associated with increased protease activity, and protease inhibitors reduced neuronal excitability. Long-lasting effects of $C$ rodentium infection seem to depend on genetic predisposition, because Th2-predominant BALB/c mice maintained visceral hypersensitivity for longer period of time than Th1-predominant C57Bl/6 mice. ${ }^{94}$ The advantages of this model are the use of a bacterial pathogen that closely resembles that involved in PI-IBS and development of hyperalgesia, but no changes in motility or permeability were shown so far.

\section{Treatment and Consensus Statements}

The RFWT performed a systematic literature search and found limited data and no existing guidelines or recommendations on specific management strategies for PI-IBS. Therefore, the RFWT adopted a Delphi process to rate quality of evidence on patient education regarding the condition and guidance on therapy, including the few specific treatments tested in controlled clinical trials in PI-IBS patients. Details on the Delphi process and statements assessed are provided in the supplementary material. The following statements were accepted:

- Statement 1 . The first step in the treatment is to educate patients about the link between intestinal infections and subsequent development of IBS.

Strong recommendation, quality of evidence moderate. Vote: strongly agree, $64 \%$; agree, $7 \%$.
- Statement 2. Reassurance should be provided, especially with suspected viral associated PI-IBS, that symptoms are likely to improve or resolve in several patients over time.

Grade: moderate recommendation, quality of evidence moderate. Vote: strongly agree, $50 \%$; agree, $21 \%$.

- Statement 3. There are no specific treatment options for PI-IBS, and treatment should be guided by treatment of IBS in general (depending upon the subtype: IBS-D, IBS-M, or rarely IBS-C).

Grade: moderate recommendation, quality of evidence moderate. Vote: strongly agree, $29 \%$; agree, $64 \%$.

In consideration of these statements, an expert opinion algorithm has been proposed and is reported in Figure 6 to guide the management of patients with PI-IBS.

\section{Summary}

We present the following summary points:

- PI-IBS is a common condition best characterized by Rome IV symptoms occurring in approximately 1 in 10 individuals immediately after and following resolution of acute infective gastroenteritis.

- To date, infectious gastroenteritis is one of the strongest risk factors for the development of IBS. The fact that incident cases of IBS can be identified after an objective

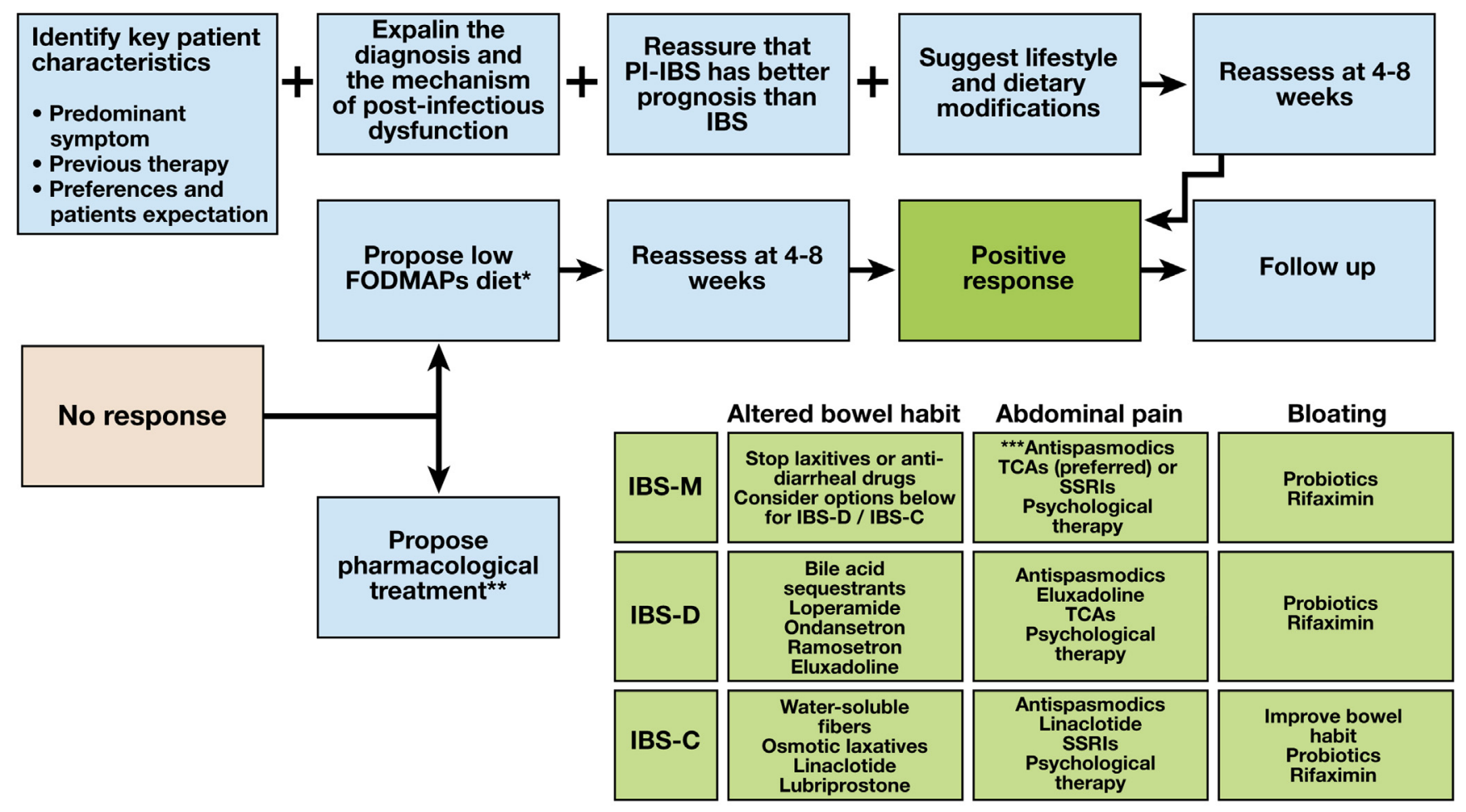

* Based on the experience of the experts, as mostof the PI-IBS are M-IBS and D-IBS, this should be first step and it is expected to be effective;

** base the sequence of treatment on predominant symptoms, preference of patient and availability of treatment; the order of

medications reflect the balance between the evidence in IBS in general and expected side effects:

*** these medications are not expected to induce either constipation or diarrhea

Figure 6. An expert consensus-based proposed treatment algorithm for PI-IBS. 
event such as infection has allowed us to move away from unfair cliché that IBS is a cryptogenic condition. The main risk factors for the development of PI-IBS include female sex, younger age, psychological factors during or before the acute gastroenteritis (e.g., anxiety, depression, somatization, neuroticism, negative illness beliefs) and severity of the acute episode (e.g., long duration of the acute episode);

- Natural history studies suggest that PI-IBS symptoms decrease over time and that the prognosis could be better than that of IBS, although the latter point is not substantiated by well-designed comparative studies.

- PI-IBS provides a unique model to study the initial stages of IBS development and investigate the mechanisms that maintain altered gut physiology and symptoms when the infection has subsided and the acute inflammatory response has weaned. The pathophysiology of PI-IBS is multifactorial (e.g., dysmotility, visceral hypersensitivity, dysbiosis, immune activation, abnormal enteroendocrine signaling, genetic factors) and, to date, has been studied only in subsets of small samples of patients and at different time points after infection.

- Animal models may lead to further identification of relevant pathophysiological factors and development of effective therapies; these include the experimental models of postinfection evoked by $T$ spiralis, $N$ brasiliensis, $C$ parvum, $G$ duodenalis, $C$ jejuni, and $C$ rodentium.

- Although limited data exist on specific treatments guidelines for PI-IBS exist, a therapeutic algorithm and consensus has been provided in the present paper.

\section{Future Considerations}

Although PI-IBS has received increasing attention, these studies are challenging. The condition is best studied prospectively, and only large outbreaks make it possible to recruit substantive numbers of patients. Future mechanistic studies should focus on pathogen-specific subgroups that could lead to identification of specific pathophysiological mechanisms. Development of biomarkers that can be used in acute stages for prevention of PI-IBS development and chronically for diagnosis and specific targeting of the PI-IBS subgroup would help prevent development and personalize treatment of PI-IBS. Finally, dietary and pharmacologic clinical trials are needed specific to this subgroup based on the unique pathophysiological characteristics. For example, enrichment with certain taxa in the fecal microbiota of IBS was associated with increased response to a diet low in fermentable oligo-, di-, and monosaccharides and polyols. ${ }^{95,96}$ Also, low-grade inflammation has been shown to predict the response to mesalazine in patients with PI-IBS. ${ }^{97}$ The role of central dysfunction in modulation peripheral responses and its targeting should be examined in PI-IBS. This subset of IBS provides a unique opportunity to determine mechanisms and design treatment strategies that can be applied more broadly to IBS and other FGIDs in future.

\section{Supplementary Material}

Note: To access the supplementary material accompanying this article, visit the online version of Gastroenterology at www.gastrojournal.org, and at https://doi.org/10.1053/ j.gastro.2018.07.011.

\section{References}

1. Drossman D. Rome IV: functional gastrointestinal disorders-disorders of gut-brain interaction. In: Drossman D, ed. 2016.

2. Hurst A. Medical diseases of the war. London: UK; E. Arnold, 1917.

3. Stewart G. Post-dysenteric colitis. Br Med J 1950; 18:405-409.

4. Chaudhary NA, Truelove SC. The irritable colon syndrome. A study of the clinical features, predisposing causes, and prognosis in 130 cases. Q J Med 1962; 31:307-322.

5. Gwee KA, Graham JC, McKendrick MW, et al. Psychometric scores and persistence of irritable bowel after infectious diarrhoea. Lancet 1996;347: 150-153.

6. Gwee KA, Leong YL, Graham C, et al. The role of psychological and biological factors in postinfective gut dysfunction. Gut 1999;44:400-406.

7. Neal KR, Hebden J, Spiller R. Prevalence of gastrointestinal symptoms six months after bacterial gastroenteritis and risk factors for development of the irritable bowel syndrome: postal survey of patients. Br Med J 1997;314:779-782.

8. Klem F, Wadhwa A, Prokop L, et al. Prevalence, risk factors, and outcomes of irritable bowel syndrome after infectious enteritis: a systematic review and meta-analysis. Gastroenterology 2017;152:1042-1054.

9. Marshall JK, Thabane M, Garg AX, et al. Incidence and epidemiology of irritable bowel syndrome after a large waterborne outbreak of bacterial dysentery. Gastroenterology 2006;131:445-450.

10. Wensaas KA, Langeland $\mathrm{N}$, Hanevik $\mathrm{K}$, et al. Irritable bowel syndrome and chronic fatigue 3 years after acute giardiasis: historic cohort study. Gut 2012;61: 214-219.

11. Shah ED, Riddle MS, Chang C, et al. Estimating the contribution of acute gastroenteritis to the overall prevalence of irritable bowel syndrome. J Neurogastroenterol Motil 2012;18:200-204.

12. Villani AC, Lemire M, Thabane M, et al. Genetic risk factors for post-infectious irritable bowel syndrome following a waterborne outbreak of gastroenteritis. Gastroenterology 2010;138:1502-1513.

13. Marshall JK, Thabane M, Garg AX, et al. Intestinal permeability in patients with irritable bowel syndrome after a waterborne outbreak of acute gastroenteritis in Walkerton, Ontario. Aliment Pharmacol Ther 2004; 20:1317-1322.

14. Dunlop SP, Hebden J, Campbell E, et al. Abnormal intestinal permeability in subgroups of diarrheapredominant irritable bowel syndromes. Am J Gastroenterol 2006;101:1288-1294. 
15. Spiller RC, Jenkins D, Thornley JP, et al. Increased rectal mucosal enteroendocrine cells, $\mathrm{T}$ lymphocytes, and increased gut permeability following acute Campylobacter enteritis and in post-dysenteric irritable bowel syndrome. Gut 2000;47:804-811.

16. Dizdar V, Spiller R, Singh G, et al. Relative importance of abnormalities of CCK and 5-HT (serotonin) in Giardiainduced post-infectious irritable bowel syndrome and functional dyspepsia. Aliment Pharmacol Ther 2010; 31:883-891.

17. Keating C, Beyak M, Foley S, et al. Afferent hypersensitivity in a mouse model of post-inflammatory gut dysfunction: role of altered serotonin metabolism. J Physiol 2008;586:4517-4530.

18. Wheatcroft J, Wakelin D, Smith A, et al. Enterochromaffin cell hyperplasia and decreased serotonin transporter in a mouse model of postinfectious bowel dysfunction. Neurogastroenterol Motil 2005;17:863-870.

19. Dunlop SP, Jenkins D, Neal KR, et al. Relative importance of enterochromaffin cell hyperplasia, anxiety, and depression in postinfectious IBS. Gastroenterology 2003;125:1651-1659.

20. Dunlop SP, Jenkins D, Spiller RC. Distinctive clinical, psychological, and histological features of postinfective irritable bowel syndrome. Am J Gastroenterol 2003; 98:1578-1583.

21. Pokkunuri V, Pimentel M, Morales $W$, et al. Role of cytolethal distending toxin in altered stool form and bowel phenotypes in a rat model of post-infectious irritable bowel syndrome. J Neurogastroenterol Motil 2012; 18:434-442.

22. Pimentel M, Chatterjee S, Chang $C$, et al. A new rat model links two contemporary theories in irritable bowel syndrome. Dig Dis Sci 2008;53:982-989.

23. Jee SR, Morales W, Low K, et al. ICC density predicts bacterial overgrowth in a rat model of post-infectious IBS. World J Gastroenterol 2010;16:3680-3686.

24. Farrugia G. Interstitial cells of Cajal in health and disease. Neurogastroenterol Motil 2008;20(Suppl 1):54-63.

25. Qin HY, Wu JC, Tong XD, et al. Systematic review of animal models of post-infectious/post-inflammatory irritable bowel syndrome. J Gastroenterol 2011;46:164-174.

26. Ibeakanma C, Ochoa-Cortes F, Miranda-Morales M, et al. Brain-gut interactions increase peripheral nociceptive signaling in mice with postinfectious irritable bowel syndrome. Gastroenterology 2011;141:20982108.

27. Wouters MM, Van Wanrooy S, Nguyen A, et al. Psychological comorbidity increases the risk for postinfectious IBS partly by enhanced susceptibility to develop infectious gastroenteritis. Gut 2016;65:12791288.

28. Dunlop SP, Jenkins D, Neal KR, et al. Randomized, double-blind, placebo-controlled trial of prednisolone in post-infectious irritable bowel syndrome. Aliment Pharmacol Ther 2003;18:77-84.

29. Tuteja AK, Fang JC, Al-Suqi M, et al. Double-blind placebo-controlled study of mesalamine in post-infective irritable bowel syndrome-a pilot study. Scand J Gastroenterol 2012;47:1159-1164.
30. Lacy BE, Mearin F, Chang L, et al. Bowel disorders. Gastroenterology 2016;150:1393-1407.

31. Spiller R, Garsed K. Postinfectious irritable bowel syndrome. Gastroenterology 2009;136:1979-1988.

32. Thabane M, Simunovic M, Akhtar-Danesh N, et al. Clustering and stability of functional lower gastrointestinal symptom after enteric infection. Neurogastroenterol Motil 2012;24:546-552.

33. Drossman DA. Improving the treatment of irritable bowel syndrome with the Rome IV Multidimensional Clinical Profile. Gastroenterol Hepatol 2017;13:694-696.

34. Thabane M, Kottachchi DT, Marshall JK. Systematic review and meta-analysis: the incidence and prognosis of post-infectious irritable bowel syndrome. Aliment Pharmacol Ther 2007;26:535-544.

35. Wadhwa A, Al Nahhas MF, Dierkhising RA, et al. High risk of post-infectious irritable bowel syndrome in patients with Clostridium difficile infection. Aliment Pharmacol Ther 2016;44:576-582.

36. Gutierrez RL, Riddle MS, Porter CK. Increased risk of functional gastrointestinal sequelae after Clostridium difficile infection among active duty United States military personnel (1998-2010). Gastroenterology 2015; 149:1408-1414.

37. Rahman M, Goshal U, Sultana S, et al. Long-term gastrointestinal consequences are frequent following sporadic acute infectious diarrhea in a tropical country: $A$ prospective cohort study. Am J Gastroenterol 2018; 113(Suppl 3):1363-1375.

38. Chogle A, Mintjens S, Saps M. Pediatric IBS: an overview on pathophysiology, diagnosis and treatment. Pediatr Ann 2014;43:e76-e82.

39. Cremon C, Stanghellini V, Pallotti F, et al. Salmonella gastroenteritis during childhood is a risk factor for irritable bowel syndrome in adulthood. Gastroenterology 2014;147:69-77.

40. Stanghellini V, Chan FK, Hasler WL, et al. Gastroduodenal disorders. Gastroenterology 2016;150:13801392.

41. Corsetti M, Caenepeel P, Fischler B, et al. Impact of coexisting irritable bowel syndrome on symptoms and pathophysiological mechanisms in functional dyspepsia. Am J Gastroenterol 2004;99:1152-1159.

42. Tack J, Demedts I, Dehondt G, et al. Clinical and pathophysiological characteristics of acute-onset functional dyspepsia. Gastroenterology 2002;122: 1738-1747.

43. Futagami S, Itoh T, Sakamoto C. Systematic review with meta-analysis: post-infectious functional dyspepsia. Aliment Pharmacol Ther 2015;41:177-188.

44. Wensaas KA, Hanevik K, Hausken T, et al. Postinfectious and sporadic functional gastrointestinal disorders have different prevalences and rates of overlap: results from a controlled cohort study 3 years after acute giardiasis. Neurogastroenterol Motil 2016; 28:1561-1569.

45. Kanazawa M, Palsson OS, van Tilburg MA, et al. Motility response to colonic distention is increased in postinfectious irritable bowel syndrome (PI-IBS). Neurogastroenterol Motil 2014;26:696-704. 
46. Lozupone CA, Stombaugh JI, Gordon Jl, et al. Diversity, stability and resilience of the human gut microbiota. Nature 2012;489:220-230.

47. Faith JJ, Guruge JL, Charbonneau M, et al. The longterm stability of the human gut microbiota. Science 2013;341:1237439.

48. Rajilic-Stojanovic M, Heilig H, Tims S, et al. Long-term monitoring of the human intestinal microbiota composition. Environ Microbiol 2013;15:1146-1159.

49. Dethlefsen L, Relman DA. Incomplete recovery and individualized responses of the human distal gut microbiota to repeated antibiotic perturbation. Proc Natl Acad Sci U S A 2011;108(Suppl 1):4554-4561.

50. Jalanka J, Salonen A, Fuentes S, et al. Microbial signatures in post-infectious irritable bowel syndrome-toward patient stratification for improved diagnostics and treatment. Gut Microbes 2015;6:364-369.

51. Dicksved J, Ellstrom P, Engstrand L, et al. Susceptibility to Campylobacter infection is associated with the species composition of the human fecal microbiota. MBio 2014;5:e01212-e1214.

52. Jeffery IB, O'Toole PW, Ohman L, et al. An irritable bowel syndrome subtype defined by species-specific alterations in faecal microbiota. Gut 2012;61:997-1006.

53. Rajilic-Stojanovic M, Biagi E, Heilig HG, et al. Global and deep molecular analysis of microbiota signatures in fecal samples from patients with irritable bowel syndrome. Gastroenterology 2011;141:1792-1801.

54. Jalanka-Tuovinen J, Salojarvi J, Salonen A, et al. Faecal microbiota composition and host-microbe cross-talk following gastroenteritis and in postinfectious irritable bowel syndrome. Gut 2014;63:1737-1745.

55. Youmans BP, Ajami NJ, Jiang ZD, et al. Characterization of the human gut microbiome during travelers' diarrhea. Gut Microbes 2015;6:110-119.

56. Schwille-Kiuntke J, Mazurak N, Enck P. Systematic review with meta-analysis: post-infectious irritable bowel syndrome after travellers' diarrhoea. Aliment Pharmacol Ther 2015;41:1029-1037.

57. Sundin J, Rangel I, Repsilber D, et al. Cytokine response after stimulation with key commensal bacteria differ in post-infectious irritable bowel syndrome (PI-IBS) patients compared to healthy controls. PLoS One 2015; 10:e0134836.

58. Kim HS, Lim JH, Park H, et al. Increased immunoendocrine cells in intestinal mucosa of postinfectious irritable bowel syndrome patients 3 years after acute Shigella infection-an observation in a small case control study. Yonsei Med J 2010;51:45-51.

59. Wang LH, Fang XC, Pan GZ. Bacillary dysentery as a causative factor of irritable bowel syndrome and its pathogenesis. Gut 2004;53:1096-1101.

60. Park JH, Rhee PL, Kim HS, et al. Mucosal mast cell counts correlate with visceral hypersensitivity in patients with diarrhea predominant irritable bowel syndrome. J Gastroenterol Hepatol 2006;21:71-78.

61. Cremon C, Gargano L, Morselli-Labate AM, et al. Mucosal immune activation in irritable bowel syndrome: gender-dependence and association with digestive symptoms. Am J Gastroenterol 2009;104:392-400.
62. Sundin J, Rangel I, Kumawat AK, et al. Aberrant mucosal lymphocyte number and subsets in the colon of post-infectious irritable bowel syndrome patients. Scand J Gastroenterol 2014;49:1068-1075.

63. Sundin J, Rangel I, Fuentes S, et al. Altered faecal and mucosal microbial composition in post-infectious irritable bowel syndrome patients correlates with mucosal lymphocyte phenotypes and psychological distress. Aliment Pharmacol Ther 2015;41:342-351.

64. Pimentel M, Morales W, Rezaie A, et al. Development and validation of a biomarker for diarrhea-predominant irritable bowel syndrome in human subjects. PLoS One 2015;10:e0126438.

65. Schoepfer AM, Schaffer T, Seibold-Schmid B, et al. Antibodies to flagellin indicate reactivity to bacterial antigens in IBS patients. Neurogastroenterol Motil 2008; 20:1110-1118.

66. Chen J, Zhang Y, Deng Z. Imbalanced shift of cytokine expression between T helper 1 and T helper 2 (Th1/Th2) in intestinal mucosa of patients with post-infectious irritable bowel syndrome. BMC Gastroenterol 2012;12:91.

67. Rajilic-Stojanovic M, de Vos WM. The first 1000 cultured species of the human gastrointestinal microbiota. FEMS Microbiol Rev 2014;38:996-1047.

68. Swan C, Duroudier NP, Campbell E, et al. Identifying and testing candidate genetic polymorphisms in the irritable bowel syndrome (IBS): association with TNFSF15 and TNFalpha. Gut 2013;62:985-994.

69. Bercik P, Wang L, Verdu EF, et al. Visceral hyperalgesia and intestinal dysmotility in a mouse model of postinfective gut dysfunction. Gastroenterology 2004; 127:179-187.

70. Vallance BA, Blennerhassett PA, Collins SM. Increased intestinal muscle contractility and worm expulsion in nematode-infected mice. Am J Physiol 1997;272:G321G327.

71. Collins SM, Blennerhassett PA, Blennerhassett MG, et al. Impaired acetylcholine release from the myenteric plexus of Trichinella-infected rats. Am J Physiol 1989; 257:G898-G903.

72. Barbara G, Vallance BA, Collins SM. Persistent intestinal neuromuscular dysfunction after acute nematode infection in mice. Gastroenterology 1997;113:1224-1232.

73. Vallance BA, Croitoru K, Collins SM. T Iymphocytedependent and -independent intestinal smooth muscle dysfunction in the T. spiralis-infected mouse. Am J Physiol 1998;275:G1157-G1165.

74. Barbara G, De Giorgio R, Deng $Y$, et al. Role of immunologic factors and cyclooxygenase 2 in persistent postinfective enteric muscle dysfunction in mice. Gastroenterology 2001;120:1729-1736.

75. Galeazzi F, Haapala EM, van Rooijen N, et al. Inflammation-induced impairment of enteric nerve function in nematode-infected mice is macrophage dependent. Am J Physiol Gastrointest Liver Physiol 2000;278: G259-G265.

76. Galeazzi F, Lovato P, Blennerhassett PA, et al. Neural change in Trichinella-infected mice is MHC II independent and involves M-CSF-derived macrophages. Am J Physiol Gastrointest Liver Physiol 2001;281:G151-G158. 
77. Akiho H, Deng $Y$, Blennerhassett $P$, et al. Mechanisms underlying the maintenance of muscle hypercontractility in a model of postinfective gut dysfunction. Gastroenterology 2005;129:131-141.

78. Der T, Bercik P, Donnelly G, et al. Interstitial cells of Cajal and inflammation-induced motor dysfunction in the mouse small intestine. Gastroenterology 2000;119:15901599.

79. Wang $X Y$, Berezin I, Mikkelsen HB, et al. Pathology of interstitial cells of Cajal in relation to inflammation revealed by ultrastructure but not immunohistochemistry. Am J Pathol 2002;160:1529-1540.

80. Yang X, Sheng L, Guan Y, et al. Synaptic plasticity: the new explanation of visceral hypersensitivity in rats with Trichinella spiralis infection? Dig Dis Sci 2009;54: 937-946.

81. Venkova K, Greenwood-van Meerveld B. Long-lasting changes in small intestinal transport following the recovery from Trichinella spiralis infection. Neurogastroenterol Motil 2006;18:234-242.

82. Gay J, Fioramonti J, Garcia-Villar R, et al. Alterations of intestinal motor responses to various stimuli after Nippostrongylus brasiliensis infection in rats: role of mast cells. Neurogastroenterol Motil 2000;12:207-214.

83. Gay J, Fioramonti J, Garcia-Villar R, et al. Enhanced intestinal motor response to cholecystokinin in postNippostrongylus brasiliensis-infected rats: modulation by CCK receptors and the vagus nerve. Neurogastroenterol Motil 2001;13:155-162.

84. McLean PG, Picard C, Garcia-Villar R, et al. Effects of nematode infection on sensitivity to intestinal distension: role of tachykinin NK2 receptors. Eur J Pharmacol 1997; 337:279-282.

85. McLean PG, Picard C, Garcia-Villar R, et al. Role of kinin $\mathrm{B} 1$ and $\mathrm{B} 2$ receptors and mast cells in post intestinal infection-induced hypersensitivity to distension. Neurogastroenterol Motil 1998;10:499-508.

86. Hillsley K, Lin JH, Stanisz A, et al. Dissecting the role of sodium currents in visceral sensory neurons in a model of chronic hyperexcitability using Nav1.8 and Nav1.9 null mice. J Physiol 2006;576:257-267.

87. Aerssens J, Hillsley K, Peeters PJ, et al. Alterations in the brain-gut axis underlying visceral chemosensitivity in Nippostrongylus brasiliensis-infected mice. Gastroenterology 2007;132:1375-1387.

88. Khaldi S, Gargala G, Le Goff L, et al. Cryptosporidium parvum isolate-dependent postinfectious jejunal hypersensitivity and mast cell accumulation in an immunocompetent rat model. Infect Immun 2009;77:5163-1569.

89. Bai J, Khaldi S, Gargala G, et al. Effects of octreotide on jejunal hypersensitivity triggered by Cryptosporidium parvum intestinal infection in an immunocompetent suckling rat model. Neurogastroenterol Motil 2011; 23:1043-1050.

90. Halliez MC, Motta JP, Feener TD, et al. Giardia duodenalis induces paracellular bacterial translocation and causes postinfectious visceral hypersensitivity. Am J Physiol Gastrointest Liver Physiol 2016;310:G574-G585.
91. Chen TL, Chen S, Wu HW, et al. Persistent gut barrier damage and commensal bacterial influx following eradication of Giardia infection in mice. Gut Pathog 2013;5:26.

92. Sung J, Morales W, Kim G, et al. Effect of repeated Campylobacter jejuni infection on gut flora and mucosal defense in a rat model of post infectious functional and microbial bowel changes. Neurogastroenterol Motil 2013;25:529-537.

93. Pimentel M, Morales W, Jee SR, et al. Antibiotic prophylaxis prevents the development of a post-infectious phenotype in a new rat model of post-infectious IBS. Dig Dis Sci 2011;56:1962-1966.

94. Mondelaers SU, Theofanous SA, Florens MV, et al. Effect of genetic background and postinfectious stress on visceral sensitivity in Citrobacter rodentium-infected mice. Neurogastroenterol Motil 2016;28:647-658.

95. Bennet SMP, Bohn L, Storsrud S, et al. Multivariate modelling of faecal bacterial profiles of patients with IBS predicts responsiveness to a diet low in FODMAPs. Gut 2017;67:872-881.

96. Chumpitazi BP, Cope JL, Hollister EB, et al. Randomised clinical trial: gut microbiome biomarkers are associated with clinical response to a low FODMAP diet in children with the irritable bowel syndrome. Aliment Pharmacol Ther 2015;42:418-427.

97. Lam C, Tan W, Leighton M, et al. A mechanistic multicentre, parallel group, randomised placebo-controlled trial of mesalazine for the treatment of IBS with diarrhoea (IBS-D). Gut 2016;65:91-99.

\section{Received March 9, 2018. Accepted July 5, 2018.}

\section{Reprint requests}

Address requests for reprints to: Giovanni Barbara, MD, Department of Medical and Surgical Sciences, St. Orsola-Malpighi Hospital, Building \#5, Via Massarenti, 9 - I-40138 Bologna, Italy. e-mail: giovanni.barbara@unibo.it; fax: 39051345864

\section{Acknowledgements}

We acknowledge Jerry Schoendorf for assistance with the illustrations and Lori Anderson for administrative assistance.

Author contributions: The working team was led by Giovanni Barbara and Grover Madhusudan. All working team members contributed equally to the manuscript and approved it in its final version.

\section{Conflicts of interest}

Giovanni Barbara has been a consultant, served on the advisory board, or received speaker's bureau fees and/or research support from Danone, Yakult, Ironwood, Malesci, Nestlé, Noos, Synergy, Alfa Wassermann, Almirall, and Shire; Grover Madhusudan has served on the advisory board or received research support from Takeda, Dong-A, Ironwood, and Napo; Premysl Bercik has been a consultant, served on the advisory board, and/or received research support from Nestlé, Allergan, Lupin Pharmaceuticals, IM HealthScience, and Innovate Biopharmaceuticals; Maura Corsetti acts as a consultant for Allergan and Kyowa Kirin and has been speaker for Shire and Menarini; Lena Ohman has served on the advisory board of Genetic Analyses and received research support from Danone and AstraZeneca. The remaining authors disclose no conflicts.

\section{Funding}

This work is supported by Rome Foundation, North Carolina. In addition, the authors would like to acknowledge the following funding sources: Italian Ministry of Education, University and Research; Fondazione del Monte di Bologna e Ravenna and IMA (to Giovanni Barbara) and National Institute of Diabetes and Digestive and Kidney Diseases K23 103911 (to Grover Madhusudan). 


\section{Supplementary Material}

\section{Clinical Features}

Differential Diagnosis. In some patients, it might be necessary to differentiate symptoms suggestive of PI-IBS from IBD. Misdiagnosing IBD is likely to be very uncommon, because a diagnosis of IBD in patients with longlasting symptoms of IBS is only approximately $2 \%{ }^{1}$ However, like IBS, new onset of IBD (Crohn's disease and ulcerative colitis) has been reported after infections with Campylobacter and Salmonella species, especially in the first year after the infection. ${ }^{2-5}$ Except for colonoscopy, fecal calprotectin has a good sensitivity and specificity to exclude IBD. ${ }^{6}$ A recent meta-analysis showed higher prevalence of celiac disease in patients reporting IBS-like symptoms compared with asymptomatic control individuals. ${ }^{7}$ Thus, celiac disease should be excluded initially with serologic testing. ${ }^{8}$ A recent meta-analysis also showed that microscopic colitis is not infrequent among patients with IBS-D or IBS-M (ie, $7 \%-10 \%$ of patients). ${ }^{9}$ Fecal calprotectin may also help with distinguishing microscopic colitis from IBS. ${ }^{10}$ However, the discriminatory power of fecal calprotectin in excluding microscopic colitis in the PI-IBS subset has not been tested. In retrospective studies, bile acid malabsorption has been found in up to $35 \%$ of patients with functional diarrhea or IBS-D. ${ }^{11-14}$ Increased bile acid delivery into the colon because of increased production or inadequate ileal reabsorption may be involved in the pathogenesis of diarrhea in these patients. The prevalence of bile acid malabsorption in PI-IBS is unknown; however, testing for it or an empiric trial of bile acid sequestrants may be warranted. Breath tests to exclude carbohydrate malabsorption may be of use in some patients, but their specific use in PI-IBS has not been evaluated. The use of breath testing to exclude small intestinal bacterial overgrowth may be of limited value given the low diagnostic accuracy of these tests. ${ }^{15}$ Although the prevalence of tropical sprue in patients who otherwise can be clinically defined as PI-IBS is unknown in developed countries, a recent study from a tropical area showed that $9 \%$ of those who undergo assessment and have 2 out of 3 positive test results (D-xylose hydrogen breath test, Sudan III stool testing, or duodenal histology) may have tropical sprue. ${ }^{16}$ Thus, tropical sprue should be considered in the appropriate clinical and geographic setting. ${ }^{17}$

\section{Risk Factors}

Demographic and Psychological Factors. Chronic fatigue was present in as many as $46 \%$ patients who developed IBS after Giardia infection ${ }^{18}$; however, this declined at the 10-year follow-up. ${ }^{19}$ Food intolerance, especially for high fermentable oligo-, di-, and monosaccharides and polyols (FODMAP) foods was commonly reported 3 years after Giardia infection (64\% vs 36\% in unexposed individual), ${ }^{20}$ although chronic Giardiasis was not excluded in this cohort of patients with PI-IBS. Other comorbid conditions specific to PI-IBS include reactive arthritis and in rare cases, Guillain-Barré syndrome. ${ }^{21}$ In a large study including 508,278 patients with a first diagnosis of gastrointestinal infection matched to a control cohort of $1,016,556$ individuals showed that all types of infection were associated with an increased risk of IBS (95\% CI, 2.19-4.25) and chronic fatigue syndrome $(95 \% \mathrm{CI}, 1.35-1.82){ }^{22}$

Females are more likely to develop PI-IBS. ${ }^{18,23-35}$ Younger age at enteritis has been associated with development of PI-IBS. ${ }^{36}$ Three studies found that smoking was not associated with the development of PI-IBS. ${ }^{23,26,37}$ Anxiety and depression at the time of enteritis assessed using the Hospital Anxiety and Depression Scale have both been found to be associated with an increased risk for PI-IBS development. ${ }^{23,24,32-35,38}$ Also, the presence of PI-IBS has been associated with greater anxiety and depression scores compared with control individuals who recovered from enteritis without developing of IBS. ${ }^{39,40}$ Other studies have reported somatization, ${ }^{24,33-35}$ neuroticism, ${ }^{34,35}$ extroversion, ${ }^{34}$ negative illness beliefs, ${ }^{24}$ and adverse life events in the preceding months before enteritis ${ }^{35}$ to be associated with an increased risk for PI-IBS development.

Enteritis Episode-Related Factors. Several studies have determined associations between enteritis symptoms and PI-IBS development, hypothesizing that those with severe enteritis are more likely to develop PI-IBS. Duration of diarrhea ( $>7$ days) has been associated with development of PI-IBS. ${ }^{25,28,30,31,41}$ Furthermore, abdominal pain during enteritis has been associated with development of PI-IBS in 3 studies, ${ }^{25,42,43}$ but not in another study. ${ }^{33}$ Three studies have shown that antibiotic use during enteritis is not associated with PI-IBS development, ${ }^{24,26,33}$ whereas 4 studies have shown the opposite. ${ }^{23,28,29,44}$ Two studies showed that bloody stools were associated with PI-IBS development, ${ }^{25,26}$ whereas 2 studies did not confirm that observation. ${ }^{28,33}$ Fever during enteritis was found to be protective for PI-IBS development after Campylobacter enteritis, ${ }^{45}$ whereas fever was associated with an increased risk in the Walkerton cohort study ${ }^{42}$ and, furthermore, was not associated with PI-IBS development in 3 other studies. ${ }^{28,33,46}$ Additionally, more extensive weight loss during enteritis has been found to be associated with increased risk of developing PI-IBS. ${ }^{25,28,42}$ Because significant heterogeneity exists among the study settings, methodologies, pathogen(s), and populations studied, it remains difficult to draw conclusions about the importance of these risk-factors.

Natural History of PI-IBS. Symptoms may last for weeks to years and affect patients' quality of life. The PI-IBS symptoms typically start as a continuum after the acute symptomatology related to enteritis is over and can persist as long as $8,{ }^{47} 10,{ }^{27}$ and $16^{39}$ years after infection. Of the individual reports, 8 studies evaluated PI-IBS risk at $>1$ time point after an episode of bacterial enteritis, $23,32,37,39,46-49$ 5 of which evaluated risk on at least 1 time point $>12$ months after enteritis. ${ }^{23,37,39,47,48}$ Compared to within 12 months, 1 of these showed similar relative risk beyond 12 months, $^{39}$ and 4 showed decreased risk, ${ }^{23,37,47,48}$ which became nonsignificant beyond 3 years. ${ }^{37,48}$ The risk remained stable within 12 months in 3 others. ${ }^{32,46,49}$ Hence, although PI-IBS can persist $>12$ months after bacterial enteritis, the magnitude of risk 
and severity of symptoms usually declines over a longer duration of follow-up. Much less is known about the evolution of the PI-IBS phenotype over time. Long-term follow-up from the Walkerton cohort showed stable clustering of symptoms at-least up to 6 years following the enteritis episode. ${ }^{50}$ It has been indicated that the prognosis of PI-IBS is good (odds ratios: 7.6 at 3 months, 5.0 at 6 months, 6.4 at 12 months, and 3.8 at 36 months), suggesting that patients with PI-IBS can expect a gradual recovery that could be better than that of IBS $^{51}$; however, well-conducted prospective comparative (PIIBS vs IBS) studies are lacking. A recent study with a 10-year follow-up after Giardia infection showed persistently high prevalence of PI-IBS. ${ }^{19}$ This is in line with similarly high rates reported in 3 previous studies from this cohort. The mechanisms for an unusually high rate of PI-IBS in short- and longterm studies after giardiasis from Norway are unclear. Persistent and undiagnosed chronic Giardia infection may offer a potential explanation, because eradication was not confirmed in all patients included in these cohorts. However, there might be other geographic or host-associated factors.

Studies on the natural history of bacterial vs viral PI-IBS have also been informative. Fewer studies have evaluated the incidence of PI-IBS after viral infection compared with those reporting after bacterial infection. ${ }^{27,42,52}$ One of these studies assessed risk at $>1$ time point after infection and found that the risk of PI-IBS was not significantly different from those unexposed at 6 months and beyond the infection. ${ }^{42}$ Noroviruses cause damage to the ileal microvilli and malabsorption but not overt mucosal inflammation like the heat-labile, cholera-like toxin of Campylobacter jejuni, which is often associated with marked mucosal damage and rectal bleeding and can be confused with ulcerative colitis. This may explain the transient nature of viral PI-IBS. ${ }^{42}$ In rats, rotavirus infection causes increased intestinal permeability and numbers of intraepithelial lymphocytes but no ulceration, with a rapid return to normal mucosal architecture. $^{53}$

\section{Treatment and Consensus Statements}

The RFWT provided strength of recommendations and quality of evidence for each statement graded as high, moderate, low, or very low using a simplified version of the Grading of Recommendation Assessment, Development and Evaluation (GRADE) approach. ${ }^{54}$ Assessments were reviewed and agreed on by 4 voting members (Giovanni Barbara, Grover Madhusudan, Maura Corsetti, and Uday Ghoshal) and evidence was graded with the aid of a consensus group composed of 14 voting members (4 RFWT members and 10 participants, mainly gastroenterologists). The entire consensus group voted anonymously on the level of agreement with specific statements using a modified Delphi process. Level of agreement was graded according to the following scale: $\mathrm{A}+$ : strongly agree; A: agree with minor reservations; A-: agree with major reservations; D-: disagree with major reservations; D: disagree with minor reservations; and $\mathrm{D}+$ : strongly disagree. A statement was accepted if $>65 \%$ of participants voted $\mathrm{A}+$ (strongly agree) or A (agree with minor reservations). The strength of recommendation of accepted statements was assigned as strong or conditional based on the GRADE approach, regardless of the absence of high-quality evidence.

\section{Recommendation Statements.}

- Statement 1. The first step in the treatment is to educate patients about the link between intestinal infections and subsequent development of IBS.

GRADE: strong recommendation, quality of evidence moderate. Vote: strongly agree, 64\%; agree, 7\%.

There is now substantial evidence indicating that acute infectious gastroenteritis may lead to the development of IBS in a subgroup of subjects. The link between infectious gastroenteritis and subsequent development of IBS should be searched in all IBS subtypes but especially among patients developing IBS-D and IBS-M symptoms acutely. Upon identification of such a link, patients should be educated about the possibility that infection was the trigger of their chronic gastrointestinal symptoms.

- Statement 2. Reassurance should be provided, especially with suspected viral-associated PI-IBS, that symptoms are likely to improve or resolve in several patients over time.

GRADE: Moderate recommendation, quality of evidence moderate. Vote: strongly agree, 50\%; agree, 21\%.

As stated (natural history paragraph), IBS symptoms can persist as long as $8,{ }^{47} 10,{ }^{27}$ and $16^{39}$ years after infection. Four out of 5 studies showed that the risk of IBS decreased over time $23,37,47,48$ and became nonsignificant beyond 3 years. $^{37,48}$ Thus, patients should be reassured and educated about the possibility that symptoms may disappear over time in most cases. This may particularly true for viral pathogens such as norovirus.

- Statement 3. There are no specific treatment options for PI-IBS, and treatment should be guided by treatment of IBS in general (depending upon the subtype: IBS-D, IBS-M, or rarely IBS-C).

GRADE: Moderate recommendation; quality of evidence moderate. Vote: strongly agree, 29\%; agree, 64\%.

There is limited evidence from the current literature indicating specific treatment strategies for PI-IBS. Because most patients with PI-IBS have the mixed- or diarrheapredominant subtype, they are treated accordingly. Nonpharmacologic measures such as elimination of foods high in FODMAPs have also been found useful in patients with IBS-D. ${ }^{55}$ Drugs used in the treatment of IBS-D may be grouped under antimotility and antidiarrheal agents, serotonin antagonists, bile acid binders, psychotropic agents, new opioid agonists, gut microbiota modulators, anti-inflammatory drugs, and mast-cell stabilizers. Although some of these drugs are currently in the experimental stage, others are widely available and are used in clinical practice.

Antispasmodics as a class have been shown to provide symptomatic, short-term relief in IBS, with studies on 
individual agents varying in quality and outcome measures; most studies did not differentiate between the types of IBS in the patients recruited. In general, peppermint oil, otilonium bromide, hyoscine bromide, cimetropium bromide, pinaverium bromide, and dicyclomine hydrochloride have been found to be more effective than placebo. ${ }^{56}$ With regard to antidiarrheal drugs such loperamide, although widely used in clinical practice, there is no definitive evidence supporting their use for relief of either diarrhea and abdominal pain in IBS-D.

IBS-D, including PI-IBS, is associated with increased serotonergic activity. ${ }^{57}$ Hence, serotonin antagonists are expected to be useful in the treatment of these IBS subtypes. In a meta-analysis, the number needed to treat with 5-HT3 antagonists such as alosetron and cilansetron to improve 1 IBS patient's symptoms was 7 (95\% CI, 5-11). ${ }^{58}$ However, serious adverse effects such as ischemic colitis associated with these serotonin antagonists precluded their widespread clinical use. Ramosetron, a safer alternative available in Japan and India, has been found to be useful in treatment of both female and male patients with IBS-D. ${ }^{59}$ A recent study found ondansetron to be useful in treatment of IBSD. ${ }^{60}$ Currently, there are no specific trials of 5-HT3 antagonists in PI-IBS patients; thus, the use of these drugs in PI-IBS remains empirical.

One third of patients with IBS-D have increased bile acid synthesis or fecal excretion, which may contribute to diarrhea. ${ }^{61}$ Cholestyramine is a widely available drug to treat bile acid malabsorption. However, compliance with cholestyramine treatment is poor because of palatability issues. An unblinded study showed that colesevelam altered hepatic bile acid synthesis and its fecal excretion, which resulted in less soft stools. ${ }^{62}$ A high response rate to colestipol treatment in patients with IBS-D in an open label study has been recently reported. ${ }^{63}$

Psychotropic drugs with anti-cholinergic activity, such the tricyclic antidepressants imipramine, desipramine, and amitriptyline $^{64}$ or the opioid agonists such as eluxadoline, ${ }^{65}$ have shown to be effective in patients with IBS-D. Lack of trials, specifically in PI-IBS, is a major limitation for specific guidelines on management of PI-IBS.

- Statement 4. Given the fact that PI-IBS is triggered by infection and microbiota may be linked to symptom development, modulation of microbiota changes with nonabsorbable antibiotics, like rifaximin, or a probiotic may be considered as the first choice.

GRADE: Statement rejected. Vote: strongly agree, 0\%; agree, $21 \%$.

Dysbiosis has been proposed in IBS in general and IBS-D in particular. $^{57,66}$ Consequently, manipulation of gut microbiota using antibiotics, probiotics, and possibly fecal microbial transplantation is an emerging method for treating IBS-D and likely PI-IBS. Some studies suggest that manipulation of gut microbiota using probiotics may improve symptoms of IBS, although more studies on probiotics in patients with IBS-D in general and PI-IBS in particular are needed. Prevention of PI-IBS after infectious gastroenteritis using antibiotics such as rifaximin has been studied only in an animal model. A recent study showed that rifaximin had anti-inflammatory effects and improved barrier function and visceral hypersensitivity in a mouse model of $T$ spiralis-induced PI-IBS and that these effects were seen regardless of effects on gut microbiota. ${ }^{67}$ Data on fecal microbial transplantation among patients with IBS-D are emerging but still lacking for PI-IBS. ${ }^{68}$

- Statement 5. Anti-inflammatory medications like mesalamine may be helpful for some patients.

GRADE: Statement rejected. Vote: strongly agree, $0 \%$; agree, $21 \%$.

In a multicenter uncontrolled study from Germany, mesalazine treatment during acute gastroenteritis caused by Shiga-like toxin-producing E coli 0104:H4 was protective against subsequent development of PI-IBS. ${ }^{69}$ A doubleblind, randomized, placebo-controlled trial, however, failed to show any benefit of mesalazine ( $2 \mathrm{~g}$ twice daily) over placebo in patients with IBS-D. However, a smaller subset of PI-IBS patients showed an improvement in abdominal pain severity and urgency score. ${ }^{70}$ In another double-blind, placebo-controlled pilot trial of 17 PI-IBS patients, there was no improvement in global symptoms or overall quality of life. ${ }^{71}$ Although a small randomized trial of prednisolone did not show improvement in symptoms of PI-IBS, it reduced intestinal EC cell and lymphocyte counts. ${ }^{72}$

\section{References}

1. Chey WD, Nojkov B, Rubenstein JH, et al. The yield of colonoscopy in patients with non-constipated irritable bowel syndrome: results from a prospective, controlled US trial. Am J Gastroenterol 2010;105:859-865.

2. Garcia Rodriguez LA, Ruigomez A, Wallander MA, et al. Detection of colorectal tumor and inflammatory bowel disease during follow-up of patients with initial diagnosis of irritable bowel syndrome. Scand J Gastroenterol 2000; 35:306-311.

3. Porter CK, Tribble DR, Aliaga PA, et al. Infectious gastroenteritis and risk of developing inflammatory bowel disease. Gastroenterology 2008;135:781-786.

4. Gradel KO, Nielsen HL, Schonheyder HC, et al. Increased short- and long-term risk of inflammatory bowel disease after salmonella or campylobacter gastroenteritis. Gastroenterology 2009;137:495-501.

5. Ternhag A, Torner A, Svensson A, et al. Short- and longterm effects of bacterial gastrointestinal infections. Emerg Infect Dis 2008;14:143-148.

6. van Rheenen PF, Van de Vijver E, Fidler V. Faecal calprotectin for screening of patients with suspected inflammatory bowel disease: diagnostic meta-analysis. BMJ 2010;341:c3369.

7. Irvine AJ, Chey WD, Ford AC. Screening for celiac disease in irritable bowel syndrome: an updated systematic review and meta-analysis. Am J Gastroenterol 2017; 112:65-76. 
8. Rubio-Tapia A, Hill ID, Kelly CP, et al. ACG clinical guidelines: diagnosis and management of celiac disease. Am J Gastroenterol 2013;108:656-676.

9. Guagnozzi D, Arias A, Lucendo AJ. Systematic review with meta-analysis: diagnostic overlap of microscopic colitis and functional bowel disorders. Aliment Pharmacol Ther 2016;43:851-862.

10. von Arnim U, Wex T, Ganzert C, et al. Fecal calprotectin: a marker for clinical differentiation of microscopic colitis and irritable bowel syndrome. Clin Exp Gastroenterol 2016:9:97-103.

11. Wedlake L, A'Hern R, Russell D, et al. Systematic review: the prevalence of idiopathic bile acid malabsorption as diagnosed by SeHCAT scanning in patients with diarrhoea-predominant irritable bowel syndrome. Aliment Pharmacol Ther 2009;30:707-717.

12. Kurien M, Evans KE, Leeds JS, et al. Bile acid malabsorption: an under-investigated differential diagnosis in patients presenting with diarrhea predominant irritable bowel syndrome type symptoms. Scand J Gastroenterol 2011;46:818-822.

13. Sinha L, Liston R, Testa HJ, et al. Idiopathic bile acid malabsorption: qualitative and quantitative clinical features and response to cholestyramine. Aliment Pharmacol Ther 1998;12:839-844.

14. Williams AJ, Merrick MV, Eastwood MA. Idiopathic bile acid malabsorption-a review of clinical presentation, diagnosis, and response to treatment. Gut 1991; 32:1004-1006.

15. Gasbarrini A, Corazza GR, Gasbarrini G, et al. Methodology and indications of $\mathrm{H} 2$-breath testing in gastrointestinal diseases: the Rome Consensus Conference. Aliment Pharmacol Ther 2009;29(Suppl 1):1-49.

16. Rahman M, Goshal U, Sultana S, et al. Long-term gastrointestinal consequences are frequent following sporadic acute infectious diarrhea in a tropical country: a prospective cohort study. Am J Gastroenterol 2018; 113(Suppl 3):1363-1375.

17. Ghoshal UC, Gwee KA. Post-infectious IBS, tropical sprue and small intestinal bacterial overgrowth: the missing link. Nat Rev Gastroenterol Hepatol 2017; 14:435-441.

18. Wensaas KA, Langeland $\mathrm{N}$, Hanevik $\mathrm{K}$, et al. Irritable bowel syndrome and chronic fatigue 3 years after acute giardiasis: historic cohort study. Gut 2012;61:214-219.

19. Litleskare S, Rortveit G, Eide GE, et al. Prevalence of irritable bowel syndrome and chronic fatigue 10 years after Giardia infection. Clin Gastroenterol Hepatol 2018; 16:1064-1072.

20. Litleskare S, Wensaas KA, Eide GE, et al. Perceived food intolerance and irritable bowel syndrome in a population 3 years after a giardiasis-outbreak: a historical cohort study. BMC Gastroenterol 2015;15:164.

21. Esan $O B$, Pearce $M$, van Hecke $O$, et al. Factors associated with sequelae of Campylobacter and nontyphoidal Salmonella infections: a systematic review. EBioMedicine 2017:15:100-111.

22. Donnachie E, Schneider A, Mehring M, et al. Incidence of irritable bowel syndrome and chronic fatigue following Gl infection: a population-level study using routinely collected claims data. Gut 2018;67:1078-1086.

23. Ruigomez A, Garcia Rodriguez LA, Panes J. Risk of irritable bowel syndrome after an episode of bacterial gastroenteritis in general practice: influence of comorbidities. Clin Gastroenterol Hepatol 2007;5:465-469.

24. Spence MJ, Moss-Morris R. The cognitive behavioural model of irritable bowel syndrome: a prospective investigation of patients with gastroenteritis. Gut 2007; 56:1066-1071.

25. Marshall JK, Thabane M, Garg AX, et al. Incidence and epidemiology of irritable bowel syndrome after a large waterborne outbreak of bacterial dysentery. Gastroenterology 2006;131:445-450.

26. Pitzurra R, Fried M, Rogler G, et al. Irritable bowel syndrome among a cohort of European travelers to resource-limited destinations. J Travel Med 2011; 18:250-256.

27. Zanini B, Ricci C, Bandera F, et al. Incidence of postinfectious irritable bowel syndrome and functional intestinal disorders following a water-borne viral gastroenteritis outbreak. Am J Gastroenterol 2012;107: 891-899.

28. Thabane M, Simunovic M, Akhtar-Danesh N, et al. An outbreak of acute bacterial gastroenteritis is associated with an increased incidence of irritable bowel syndrome in children. Am J Gastroenterol 2010; 105:933-939.

29. Tornblom H, Holmvall P, Svenungsson B, et al. Gastrointestinal symptoms after infectious diarrhea: a five-year follow-up in a Swedish cohort of adults. Clin Gastroenterol Hepatol 2007;5:461-464.

30. Ji S, Park H, Lee D, et al. Post-infectious irritable bowel syndrome in patients with Shigella infection. J Gastroenterol Hepatol 2005;20:381-386.

31. Neal KR, Hebden J, Spiller R. Prevalence of gastrointestinal symptoms six months after bacterial gastroenteritis and risk factors for development of the irritable bowel syndrome: postal survey of patients. Br Med J 1997;314:779-782.

32. Moss-Morris R, Spence M. To "lump" or to "split" the functional somatic syndromes: can infectious and emotional risk factors differentiate between the onset of chronic fatigue syndrome and irritable bowel syndrome? Psychosom Med 2006;68:463-469.

33. Nielsen HL, Engberg J, Ejlertsen T, et al. Psychometric scores and persistence of irritable bowel after Campylobacter concisus infection. Scand J Gastroenterol 2014;49:545-551.

34. Gwee KA, Graham JC, McKendrick MW, et al. Psychometric scores and persistence of irritable bowel after infectious diarrhoea. Lancet 1996;347:150-153.

35. Gwee KA, Leong YL, Graham C, et al. The role of psychological and biological factors in postinfective gut dysfunction. Gut 1999;44:400-406.

36. Thabane M, Simunovic M, Akhtar-Danesh $\mathrm{N}$, et al. Development and validation of a risk score for postinfectious irritable bowel syndrome. Am J Gastroenterol 2009;104:2267-2274. 
37. Jung IS, Kim HS, Park H, et al. The clinical course of postinfectious irritable bowel syndrome: a five-year follow-up study. J Clin Gastroenterol 2009;43:534-540.

38. Schwille-Kiuntke J, Enck P, Zendler C, et al. Postinfectious irritable bowel syndrome: follow-up of a patient cohort of confirmed cases of bacterial infection with Salmonella or Campylobacter. Neurogastroenterol Motil 2011;23:e479-e488.

39. Cremon C, Stanghellini V, Pallotti F, et al. Salmonella gastroenteritis during childhood is a risk factor for irritable bowel syndrome in adulthood. Gastroenterology 2014:147:69-77.

40. Wadhwa A, Al Nahhas MF, Dierkhising RA, et al. High risk of post-infectious irritable bowel syndrome in patients with Clostridium difficile infection. Aliment Pharmacol Ther 2016;44:576-582.

41. Wang LH, Fang XC, Pan GZ. Bacillary dysentery as a causative factor of irritable bowel syndrome and its pathogenesis. Gut 2004;53:1096-1101.

42. Marshall JK, Thabane M, Borgaonkar MR, et al. Postinfectious irritable bowel syndrome after a food-borne outbreak of acute gastroenteritis attributed to a viral pathogen. Clin Gastroenterol Hepatol 2007;5:457-460.

43. Kowalcyk BK, Smeets HM, Succop PA, et al. Relative risk of irritable bowel syndrome following acute gastroenteritis and associated risk factors. Epidemiol Infect 2014;142:1259-1268.

44. Stermer E, Lubezky A, Potasman I, et al. Is traveler's diarrhea a significant risk factor for the development of irritable bowel syndrome? A prospective study. Clin Infect Dis 2006;43:898-901.

45. Bettes N, Griffith J, Camilleri M, et al. Risk and predictors of post-infectious irritable bowel syndrome among community-acquired cases of bacterial enteritis. Gastroenterology 2014;146(5):S538.

46. Koh SJ, Lee DH, Lee SH, et al. Incidence and risk factors of irritable bowel syndrome in community subjects with culture-proven bacterial gastroenteritis. Korean J Gastroenterol 2012;60:13-18.

47. Marshall JK, Thabane M, Garg AX, et al. Eight year prognosis of postinfectious irritable bowel syndrome following waterborne bacterial dysentery. Gut 2010; 59:605-611.

48. Youn Y, Park S, Park C, et al. The clinical course of postinfectious irritable bowel syndrome (IBS) after shigellosis: a 10-year follow-up study. Neurogastroenterol Motil 2012;24:102.

49. Parry SD, Stansfield R, Jelley D, et al. Does bacterial gastroenteritis predispose people to functional gastrointestinal disorders? A prospective, community-based, case-control study. Am J Gastroenterol 2003;98:19701975.

50. Thabane M, Simunovic M, Akhtar-Danesh N, et al. Clustering and stability of functional lower gastrointestinal symptom after enteric infection. Neurogastroenterol Motil 2012;24:546-552.

51. Neal KR, Barker L, Spiller RC. Prognosis in post-infective irritable bowel syndrome: a six year follow up study. Gut 2002;51:410-413.
52. Porter CK, Faix DJ, Shiau D, et al. Postinfectious gastrointestinal disorders following norovirus outbreaks. Clin Infect Dis 2012;55:915-922.

53. Salim AF, Phillips AD, Walker-Smith JA, et al. Sequential changes in small intestinal structure and function during rotavirus infection in neonatal rats. Gut 1995;36: 231-238.

54. Guyatt GH, Oxman AD, Vist GE, et al. GRADE: an emerging consensus on rating quality of evidence and strength of recommendations. BMJ 2008;336:924-926.

55. Halmos EP, Power VA, Shepherd SJ, et al. A diet low in FODMAPs reduces symptoms of irritable bowel syndrome. Gastroenterology 2014;146:67-75.

56. Ford AC, Moayyedi P, Lacy BE, et al. American College of Gastroenterology monograph on the management of irritable bowel syndrome and chronic idiopathic constipation. Am J Gastroenterol 2014;109(Suppl 1): S2-S26.

57. Barbara G, Feinle-Bisset C, Ghoshal UC, et al. The intestinal microenvironment and functional gastrointestinal disorders. Gastroenterology 2016;150:1305-1318.

58. Ford AC, Brandt LJ, Young C, et al. Efficacy of 5-HT3 antagonists and 5-HT4 agonists in irritable bowel syndrome: systematic review and meta-analysis. Am J Gastroenterol 2009;104:1831-1843.

59. Min YW, Rhee PL. The clinical potential of ramosetron in the treatment of irritable bowel syndrome with diarrhea (IBS-D). Therap Adv Gastroenterol 2015;8:136-142.

60. Garsed K, Chernova J, Hastings M, et al. A randomised trial of ondansetron for the treatment of irritable bowel syndrome with diarrhoea. Gut 2014;63:1617-1625.

61. Mottacki N, Simrén M, Bajor A. Review article: bile acid diarrhoea-pathogenesis, diagnosis and management. Aliment Pharmacol Ther 2016;43:884-898.

62. Camilleri M, Acosta A, Busciglio I, et al. Effect of colesevelam on faecal bile acids and bowel functions in diarrhoea-predominant irritable bowel syndrome. Aliment Pharmacol Ther 2015;41:438-448.

63. Bajor A, Tornblom H, Rudling M, et al. Increased colonic bile acid exposure: a relevant factor for symptoms and treatment in IBS. Gut 2015;64:84-92.

64. Drossman DA, Tack J, Ford AC, et al. Neuromodulators for functional Gl disorders (disorders of gut-brain interaction): A Rome Foundation Working Team Report. Gastroenterology 2018;154:1140-1171.

65. Keating GM. Eluxadoline: a review in diarrhoeapredominant irritable bowel syndrome. Drugs 2017; 77:1009-1016.

66. Ghoshal U, Shukla R, Srivastava D, et al. Irritable bowel syndrome, particularly the constipation-predominant form, involves an increase in Methanobrevibacter smithii, which is associated with higher methane production. Gut Liver 2016;10:932-938.

67. Jin Y, Ren X, Li G, et al. Beneficial effects of rifaximin in postinfectious irritable bowel syndrome mouse model beyond gut microbiota. J Gastroenterol Hepatol 2018; 33:443-452.

68. Johnsen PH, Hilpusch F, Cavanagh JP, et al. Faecal microbiota transplantation versus placebo for moderate- 
to-severe irritable bowel syndrome: a double-blind, randomised, placebo-controlled, parallel-group, singlecentre trial. Lancet Gastroenterol Hepatol 2018;3:17-24.

69. Andresen V, Lowe B, Broicher W, et al. Post-infectious irritable bowel syndrome (PI-IBS) after infection with Shiga-like toxin-producing Escherichia coli (STEC) 0104:H4: A cohort study with prospective follow-up. United European Gastroenterol J 2016;4:121-131.

70. Lam $\mathrm{C}$, Tan $\mathrm{W}$, Leighton $\mathrm{M}$, et al. A mechanistic multicentre, parallel group, randomised placebo-controlled trial of mesalazine for the treatment of IBS with diarrhoea (IBS-D). Gut 2016;65:91-99.

71. Tuteja AK, Fang JC, Al-Suqi M, et al. Double-blind placebo-controlled study of mesalamine in post-infective irritable bowel syndrome-a pilot study. Scand J Gastroenterol 2012;47:1159-1164.

72. Dunlop SP, Jenkins D, Neal KR, et al. Randomized, double-blind, placebo-controlled trial of prednisolone in post-infectious irritable bowel syndrome. Aliment Pharmacol Ther 2003;18:77-84. 


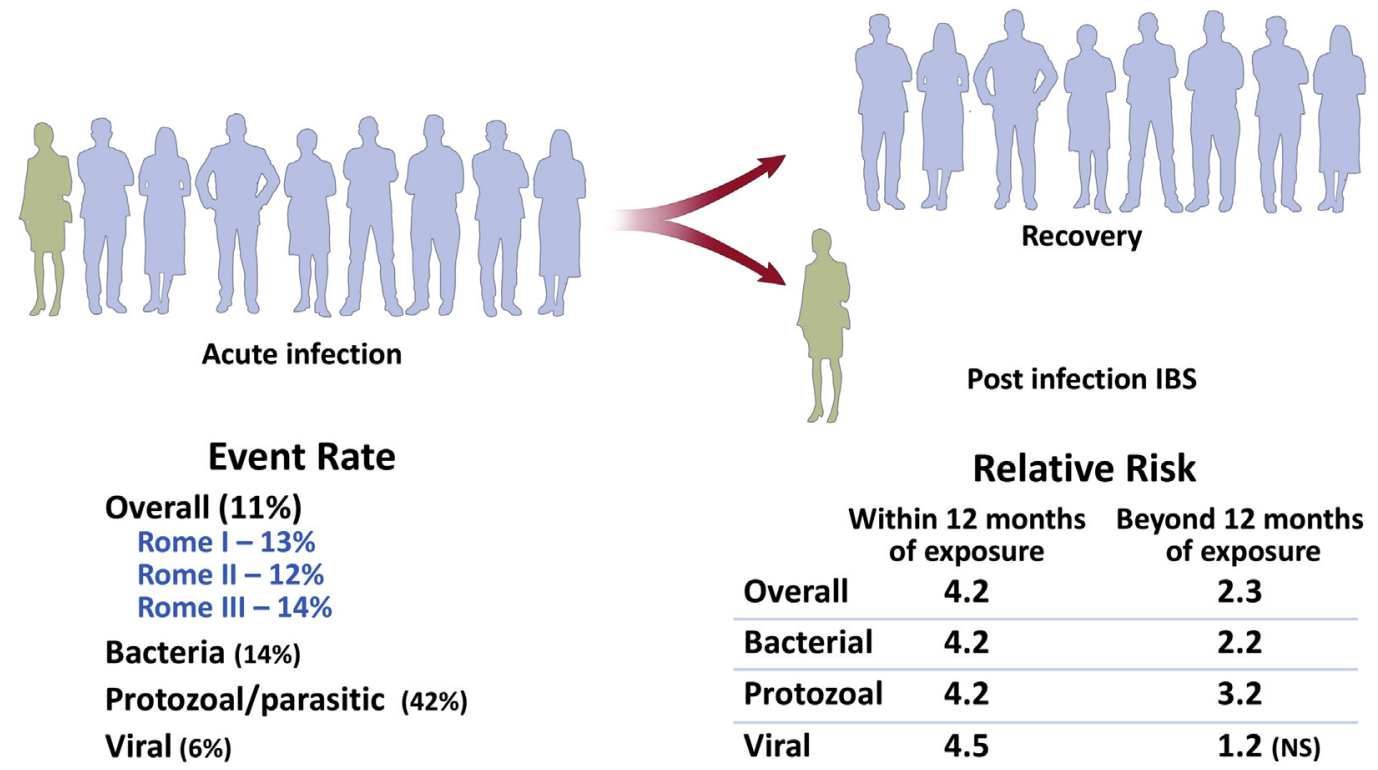

Supplementary Figure 1. Postinfection irritable bowel syndrome prevalence with pathogen type and relative risk compared with unexposed cohort in studies examining within 12 months and beyond 12 months after the episode of infectious enteritis. 